\title{
NBS TYPE II RF POWER METER OPERATION AND MAINTENANCE
}

Neil T. Larsen

Electromagnetics Division stitute for Basic Standards

National Bureau of Standards

Boulder, Colorado 80302

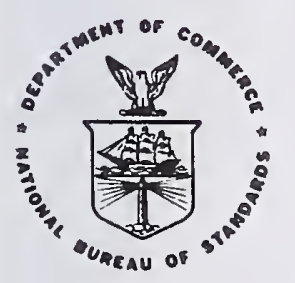

U.S. DEPARTMENT OF COMMERCE, Juanita M. Kreps, Secretary Sidney Harman, Under Secretary Jordan J. Baruch, Assistant Secretary for Science and Technology

NATIONAL BUREAU OF STANDARDS, Ernest Ambler, Acting Director 
-

-

○ 
NBS TYPE IV POWER METER

OPERATION AND MAINTENANCE

CONTENTS

Page

LIST OF FIGURES AND TABLES--

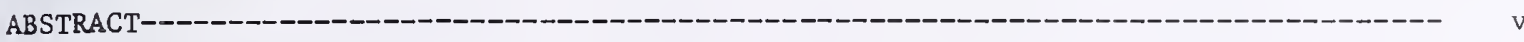

SECTION I. GENERAL INFORMATION--

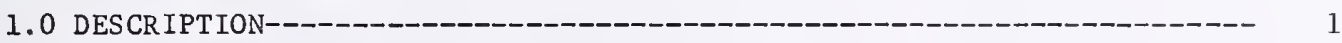

SECTION II. OPERATING INFORMATION--

2.0 INTRODUCTION---_-- 1

2.1 PRELIMINARY OPERATING INSTRUCTIONS----

2.2 BASIC POWER MEASUREMENT---- 1

2.3 PRECISION POWER MEASUREMENT---

SECTION III. MAINTENANCE AND CALIBRATION--

3.1 INTRODUCTION-_-- 9

3.2 TEST EQUIPMENT--- 9

3.3 INITIAL SETUP----- 3

3.4 POWER SUPPLY PERFORMANCE (FIG. 3-1)

3.5 AMPLIFIER OFFSET ADJUSTMENT (FIG. 3-3)-------- 10

3.6 CURRENT INDICATOR (FIG. 3-3)--- 11

3.7 CALIBRATION OF INTERNAL RESISTORS (FIG. 3-3\&3-4)------------- 11

3.8 GAIN AND NOISE TESTS-----

3.9 TEST OF INTERFACE LOGIC (FIG. 3-2)-- 13

3.10 NONSTANDARD COMPONENTS-

APPENDIX-- 
-

$\bullet$ 
Figure 2.1.

Control identification-

Figure 2.2.

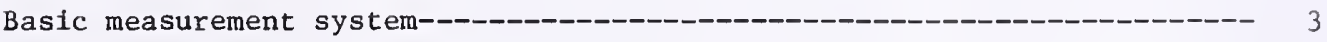

Figure 2-3. Precision measurement system using reference voltage generator (RVG)---- 5

Figure 2-4. Typical voltage measurement sequence providing first-order compensation for temperature drifts---_---_- 7

Figure 3-la. Power supply drawing, serial number 122 and below.------------------- 15

Figure 3-1b. Power supply drawing, serial numbers 123 and above-------------------- 16

Figure 3-2. Interface and mount operating resistance logic----------------------- 17

Figure 3-3. Analog cicuitry for the self-balancing current loop------------------ 18

Figure 3-4. Simplified diagram of analog circuits during calibration procedure------ 19

Figure A-1. Parts placement diagram, large board-------------------------------- 20

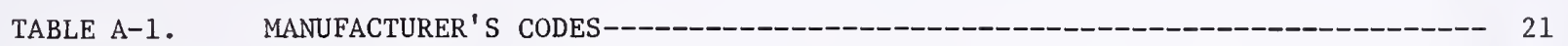

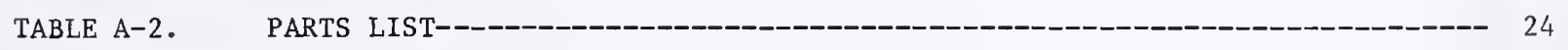

TABLE A-3. CONNECTOR PIN ASSIGNMENTS------------------------------------ 27

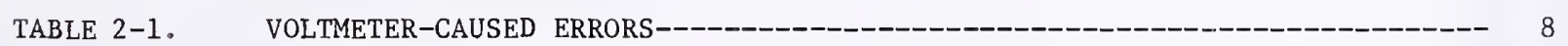


NBS TYPE IV POWER METER

OPERATION AND MAINTENANCE

\section{Ne11 T. Larsen}

Operating, maintenance, and callbration procedures are provided for the NBS Type IV Power Meter. This is a recently developed instrument for rf power measurement by means of dc substitution in a bolometer (thermistor type only). Complete parts 11sts, schematic dlagrams, and parts placement drawings are provided. Mechanical drawings are not included, but are avallable from: National Technical Information Service, U. S. Department of Commerce, 425 Thirteenth Street, N. W., Washington, D. C., 20004.

Key Words: Bolometer; dc substitution; mlcrowave; power meter.

\section{IMPORTANT NOTICE}

The speciflc components selected for the prototype instruments were chosen on the basis of sultability, availability, and cost. They do not necessarily represent the only possible choices, or even the best cholces. The National Bureau of Standards states only that they were used in the instruments described here. Substitution of nominally equivalent components meeting the same specifications should normally cause no djfficulty; however, NBS has not tested all such possible choices.

NOTE: References to serial numbers apply only to units built by NBS. 
SECTION I

GENERAL INFORMATION

\title{
1.0 DESCRIPTION
}

The NBS Type IV RF Power Meter is designed to measure high-frequency or microwave power in conjunction with an external thermistor mount. The mount should be designed to operate at a dc resistance of either 100 or 200 ohms. A complete power measurement system will also include an accurate dc voltmeter and some means of offsetting the voltmeter so that small voltage changes may be measured more accurately. This offsetting voltage source, or reference voltage generator (RVG), is particularly important when measuring power levels below a few milliwatts.

The Type IV, unlike its predecessors, is not a self-balancing Wheatstone bridge. Instead, it passes a current through the bolometer mount while sensing the voltage across it in such a way that the resistance of the bolometer is defined at the dc terminals of the bolometer, even at the ends of long leads. This eliminates the lead errors associated with a bridge. In addition, because of this new configuration, it is now possible to change the mount operating resistance with solid state switches. Therefore, the Type IV is well suited to applications requiring high accuracy and where control by a computer is used.

\author{
SECTION II \\ OPERATING INFORMATION
}

\subsection{INTRODUCTION}

The NBS Type IV Power Meter is a standards laboratory quality instrument used to measure accurately high-frequency or microwave power in terms of substituted dc power. The instrument is not direct reading; the power must be calculated, generally using data obtained from an external precision voltmeter. The Type IV is intended to be used with non-temperaturecompensated mounts. Two units can be used for compensated mounts (one for measurement and one for compensation). In most automated applications, the speed of measurement 1 s such that compensation is not required. The frequency and power range is, of course, dictated by the thermistor mount used. The Type IV can supply up to $30 \mathrm{~mA}$ of bias current to the bolometer. This corresponds to $90 \mathrm{~mW}$ in 100 ohms, or $180 \mathrm{~mW}$ in 200 ohms.

\subsection{PRELIMINARY OPERATING INSTRUCTIONS}

See Figure 2.1 for the location and function of the front and rear panel controls. Before connecting the Type IV to the ac power line, check the line voltage selector for the proper setting and the fuse for the proper value. Remove the line cord, slide the window to the left and eject the fuse. The line voltage is selected by proper orientation of the small printed circuit card, which may be pulled after removing the fuse. Line voltages of nominally 100, 120, 220, and 240 may be selected. (Note: In units with serial numbers 122 and below, and using power transformer part number 13575, the 100-volt option is not available). Line voltage tolerance is plus or minus $10 \%$. For $100-120$ volt operation, a $1 / 8$ A fast-acting fuse, $6.35 \mathrm{~mm}$ by $31.75 \mathrm{~mm}$ ( 0.25 by 1.25 inches) is used. For $220-240$ volt operation, a $1 / 16$ A fuse isquired.

\subsection{BASIC POWER MEASUREMENT}

1. With the instrument turned off, attach the thermistor mount to either the front panel binding posts or the rear connector. (See Appendix I for connector pin designations). If it is desired to use a 4-terminal connection to the mount to eliminate lead resistance errors, open the two links. The current-carrying conductors are connected to the red (positive) and black (negative) BOLOM binding posts. The sense leads are connected to the corresponding blue SENSE binding posts. Leads should be shielded to prevent noise pickup. Connect the shield to the black binding post and leave the other end open. See Figure 2.2.

2. Attach the positive and negative input leads of the external voltmeter to the red and black binding posts marked DVM. Note that it is necessary that the voltmeter 


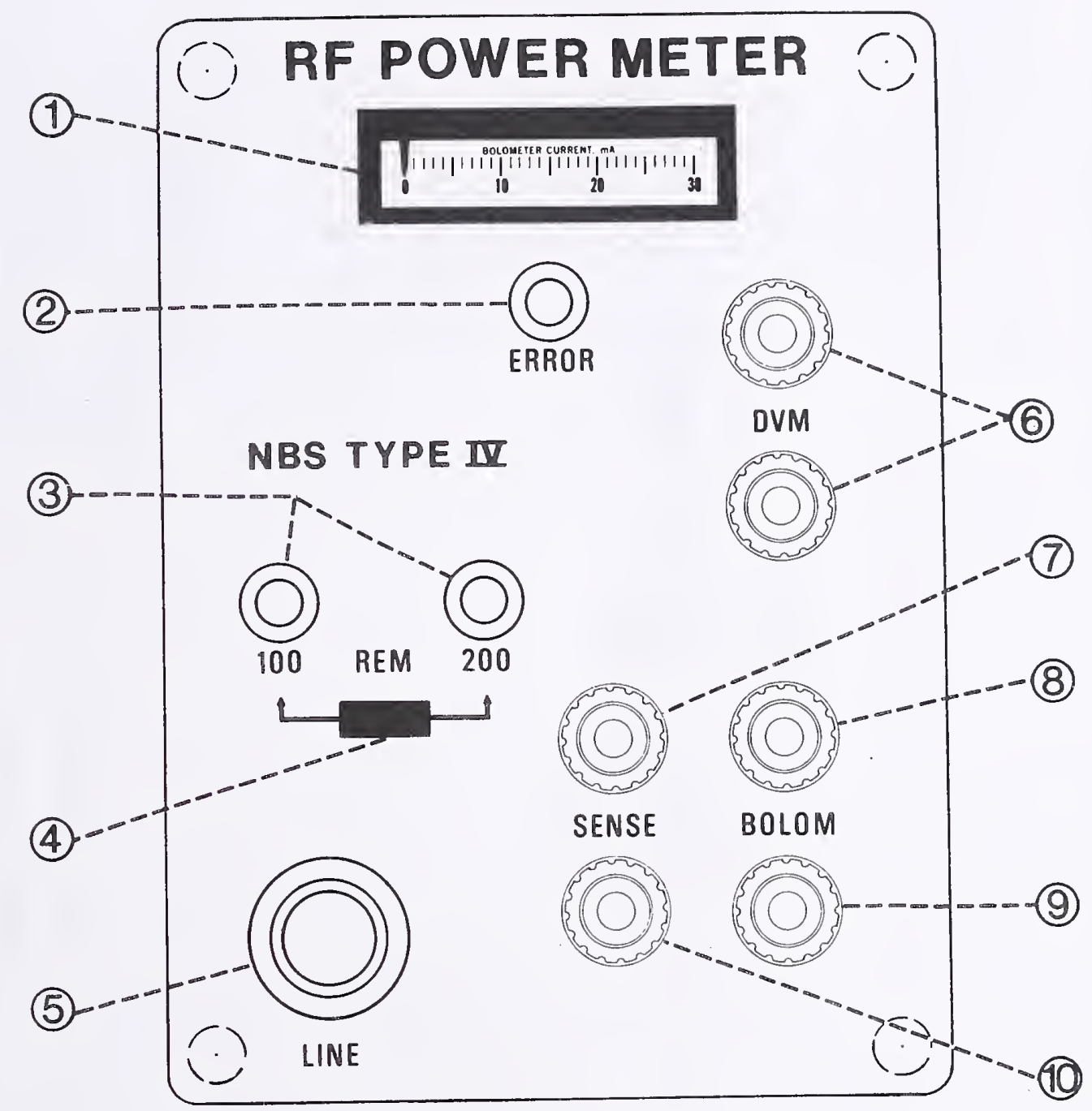

Figure 2-1. Control identification

1. Bolometer current indicator, 0-30 mA.

2. ERROR indicator. Lights red on any fault condition preventing loop balanc

3. Mount operating resistance indicators (green).

4. Mount operating resistance switch: 100 ohms, REMOTE, 200 ohms 。

5. Line power switch (push-push).

6. DVM terminals, for external voltmeter.

7. Positive bolometer voltage sense lead.

8. Positive bolometer current lead.

9. Negative bolometer current lead.

10. Negative bolometer voltage sense lead.

Front panel links connecting respective sense and current leads are not shown. 


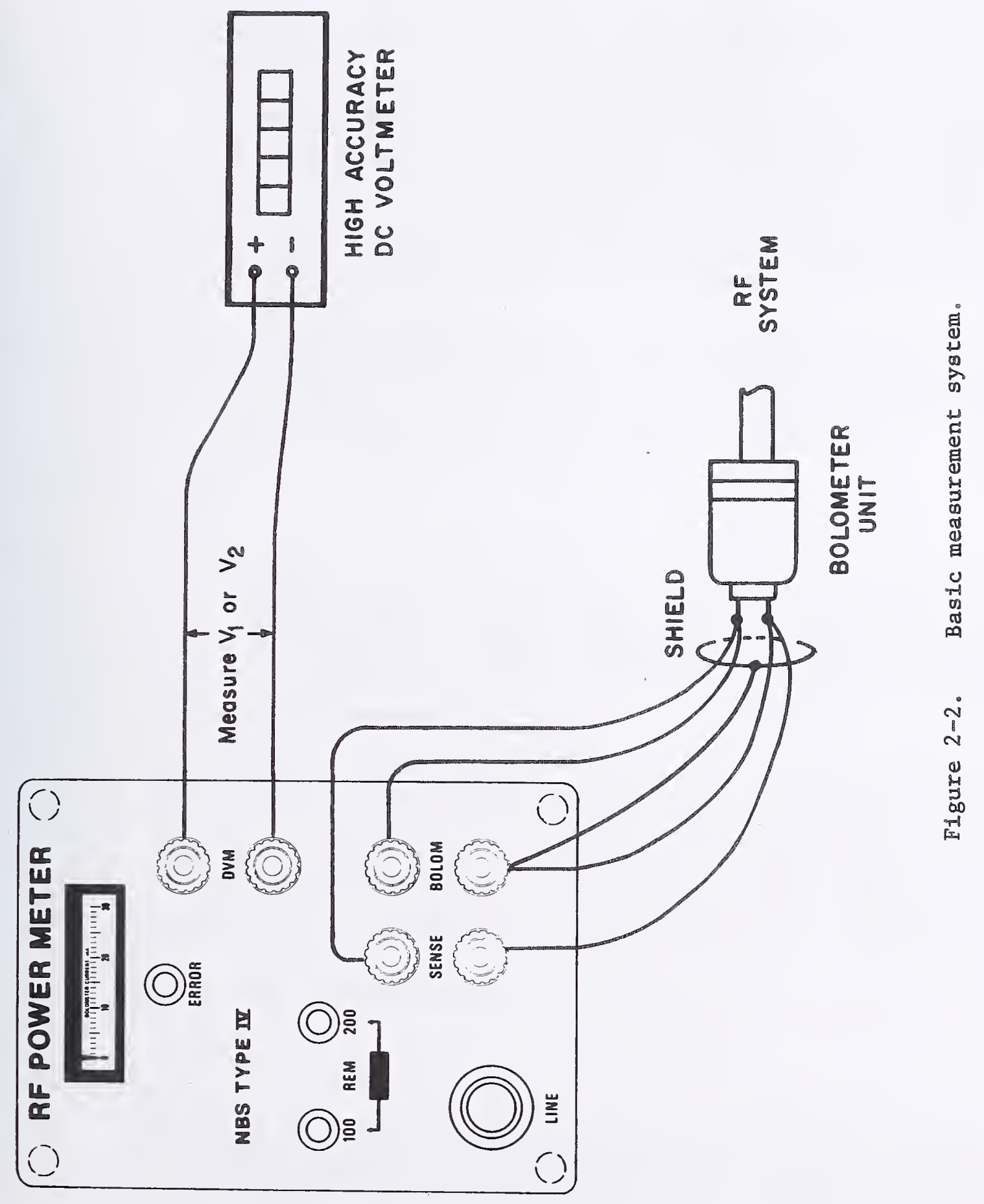


be isolated from ground, and note also that while the source resistance presented to the voltmeter by the Type IV is very low, any current drawn by the voltmeter flows through the sense lead (if used) connected to the low side of the thermistor mount. This current produces a voltage drop in the lead which causes an error. Since most digital voltmeters have very high input impedances, this is not a problem; however, it should be kept in mind that the two black terminals on the front of the instrument are not common to each other, but are connected through either the link or the sense and current leads of the cable to the mount.

3. Set the slide switch $\mathrm{S} 101$ to the 100 to $200 \mathrm{ohm}$ position, as appropriate for the mount. On the rear, set the toggle switch $\$ 202$ to the FLOAT position.

4. Turn the line power on by pressing the LINE switch S201. The correct green lamp should 1ight, indicating the mount operating resistance. The panel meter should indicate the thermistor current. The external voltmeter should show a reading equal to the product of the thermistor current and the mount operating resistance. The ERROR lamp should be dark. If incorrect, open, or shorted connections have been made, or if the mount is open (i.e., burned out), the ERROR indicator will light. It will also light under conditions of rf power overload, or any other condition which results in the balancing servo of the instrument being unable to achieve a balance between the mount resistance and the internal resistance standard.

5. To measure rf power, record the voltmeter reading, apply the $\mathrm{rf}$ power, and read again. If temperature compensation is desired, a third reading may be taken with the power off again, and the first and third readings averaged. This assumes, for example, a linear drift in voltage with time, and an equal length of time between measurements. Then, the power, $\mathrm{P}$, is given by

$$
P=\left(V_{1}^{2}-v_{2}^{2}\right) / R_{0}
$$

where $V_{1}$ is the output voltage in the absence of $\mathrm{rf}$ power (or the averaged readings mentioned above), $V_{2}$ is the voltage in the presence of $\mathrm{rf}$ power, and $\mathrm{R}_{0}$ is the mount operating resistance. Thus, the so-called "bolometric power" is simply the change in the $\mathrm{dc}$ power in the mount. The appropriate calibration factor for the mount must be applied to this number to obtain the true rf power.

\subsection{PRECISION POWER MEASUREMENT}

It is apparent from equation (1) above, that as the $\mathrm{rf}$ power becomes $\operatorname{sma} 11, \mathrm{~V}_{2}$ approaches $\mathrm{V}_{1}$. This has serious consequences for measurement accuracy. The magnification of the voltmeter uncertainties when it is used to measure two voltages which differ only slightly can be seen from Table 2-1, below. For this computation, a typical 200-ohm mount with a nominal bias current of $12.75 \mathrm{~mA}$ was assumed. The voltmeter specifications included: ranges of 0.1 , 1 , and 10 volts, with uncertainties of $0.01 \%$ of reading on all ranges, plus $0.005 \%$ of $\mathrm{full}$ scale on the $0.1 \mathrm{~V}$ range, and $0.002 \%$ of ful1 scale on the 1 and $10 \mathrm{~V}$ ranges. At $1 \mathrm{~mW}$, for example, the error due to the voltmeter is on $1 y 0.04 \%$ when an RVG is used; however, it is $2.3 \%$ without one.

When connected as shown in Figure 2-3, the power equation is modified to

$$
P=\left(2 v_{1}-v_{3}\right) v_{3} / R_{0}
$$

where $V_{3}=V_{1} w_{2}$. The differencing between $V_{1}$ and $V_{2}$ is now done electrically, rather than in the computation, so that the voltmeter is operating at a much larger fraction of ful1scale. This minimizes the uncertainty contribution of the percent-of-fullscale specification. In effect, the RVG is used to store $V_{1}$. The procedure is similar to that in Section 2.2. 


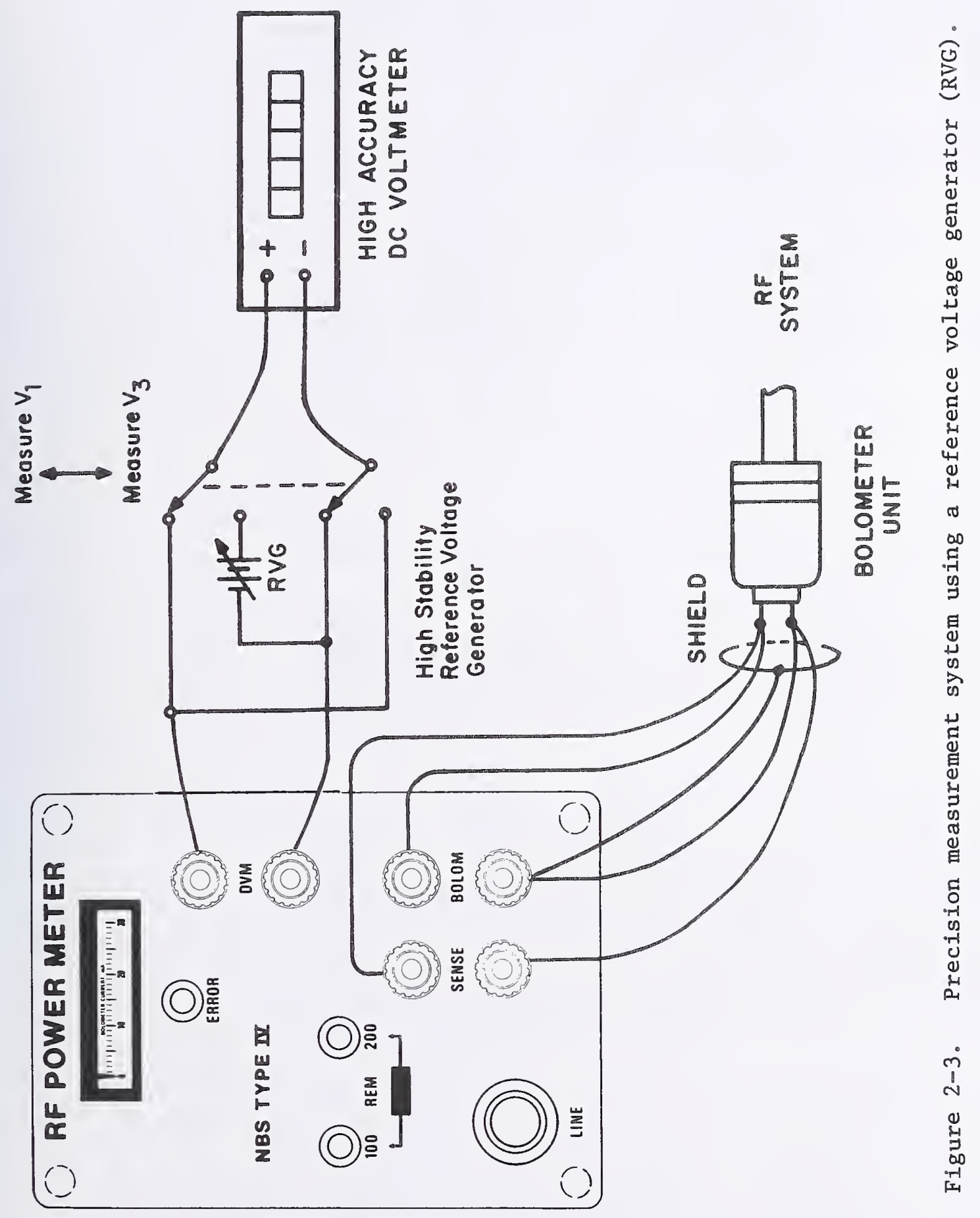


1. Attach the bolometer mount as described in Section 2.2. Connect the negative side of a stable voltage source (RVG) to the black DVM terminal, as shown in Figure 2-3. Arrange switching to allow the voltmeter to be connected either across the DVM terminals, or between the positive side of the RVG and the red DVM terminal.

2. Adjust the RVG so that its output is approximately equal to the output of the Type IV when no $\mathrm{rf}$ power is present. The object is to make any residual offset small compared to the lowest range on the voltmeter to be used, e.g., $10 \mathrm{mV}$ on a $100 \mathrm{mV}$ range. The residual offset will not cause an error, being removed in the calculation of the power from the voltmeter readings. Although it is not necessary to know exactly what the RVG output is, it is very important that the output remain stable during the time required for a measurement. Drifts should be held to less than $10 \mathrm{ppm}$.

3. To measure $\mathrm{rf}$ power with the highest accuracy and minimum sensitivity to temperature effects, the following steps are performed, usually under the control of a calculator or small computer. (Figure 2-4 summarizes these steps.)

3a. Read and record the Type IV odtput with no rf power $\left(V_{1}^{\prime}\right)$.

3b. Read and record the voltage difference between the Type IV output and the output of the RVG, still with no $\mathrm{rf}$ power $\left(\mathrm{V}_{\mathrm{d}}^{\prime}\right)$.

3c. Turn on the rf power. Again read the voltage difference between the Type IV output and the output of the RVG $\left(V_{d}\right)$.

3d. With the rf power still off, repeat step $3 b$ to obtain $V_{d}^{\prime \prime}$.

3e. Turn off the rf power and repeat step $3 a$ to get $V_{1}^{\prime \prime}$.

4. Compute the bolometric power using equation (2), as follows:

4a. For $V_{1}$, use the average value of $V_{1}^{\prime}$ and $V_{1}^{\prime \prime}$. This provides first-order compensation for temperature-induced drifts.

4b. For $V_{3}$, use $V_{d}-\left(V_{d}^{\prime}+V_{d}^{\prime \prime}\right) / 2$. The term $\left(V_{d}^{\prime}+V_{c}^{\prime \prime}\right) / 2$ is the average value of the difference voltage with no $\mathrm{rf}$ and also gives first-order temperature compensation. Subtracting this average from $V_{d}$ gives the true change in the output of the power meter, compensated for linear temperature changes and corrected for any initial offset due to inexact setting of the RVG. Eq. (2) now becomes

$$
P=\left[\left(V^{\prime}+V^{\prime \prime}\right)-V_{d}+\left(V_{d}^{\prime}+V_{d}^{\prime \prime}\right) / 2\right] \cdot\left[V_{d}-\left(V_{d}^{\prime}+V_{d}^{\prime \prime}\right) / 2\right] / R_{0} \cdot
$$

This sequence may be modified in the software to accomodate specific situations. For example, if the bolometer mount is in a closely controlled environment, compensation may be unnecessary, and the measurement process can be speeded by eliminating unnecessary voltage readings. If the RVG is a very accurate digital-to-analog convertor (DAC), then it may be possible to rely in its calibration accuracy. In general, however, the voltmeter will be considerably more accurate than the DAC, and it is better to actually measure $V_{1}$ and $V_{3}$ than to trust the DAC. Another possible compromise is to take several readings with rf power on for every reading without it, especially, if the temperature is drifiting only slowly. 


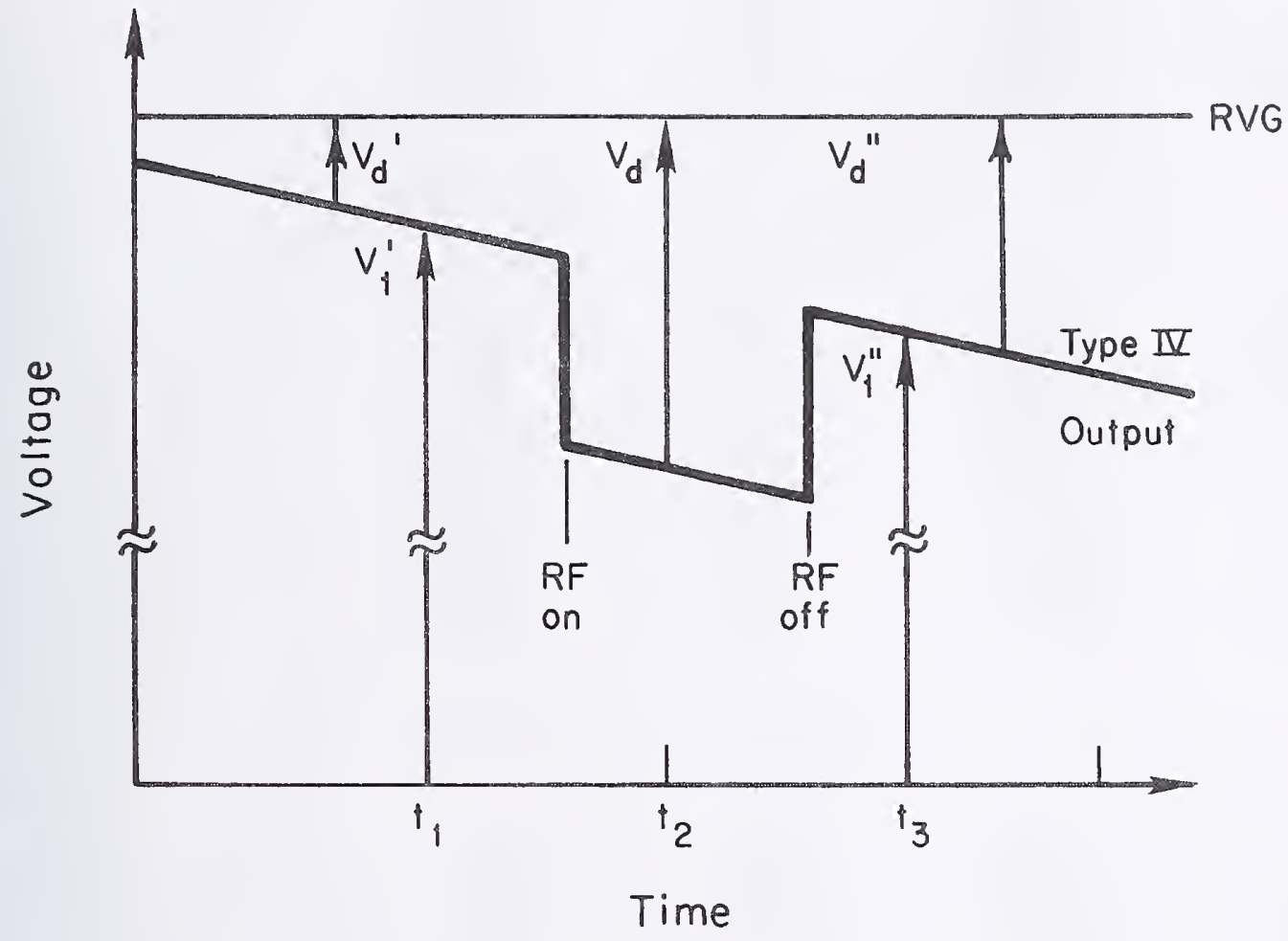

Figure 2-4. Typical voltage measurement sequence providing first-order compensation for temperature drifts. Symbols shown in the figure as the same as used in equation (3). In automatic systems, software techniques can often substitute for hardware, for temperature compensation, for example. Taking these five voltage readings with a data logger or minicomputer greatly reduces the need for precise temperature control of the bolometer mounts, while not seriously decreasing the speed. 


$\begin{array}{lrrrr}\text { P, mW } & \text { ERROR, } 8 & \text { V1 RANGE } & \text { V2 RANGE } & \text { V3 RANGE } \\ 0.100 & 0.1552 & 10.0000 & 10.0000 & 0.1000 \\ 0.200 & 0.0914 & 10.0000 & 10.0000 & 0.1000 \\ 0.300 & 0.0702 & 10.0000 & 10.0000 & 0.1000 \\ 0.400 & 0.0595 & 10.0000 & 10.0000 & 0.1000 \\ 0.500 & 0.0532 & 10.0000 & 10.0000 & 0.1000 \\ 0.600 & 0.0489 & 10.0000 & 10.0000 & 0.1000 \\ 0.700 & 0.0459 & 10.0000 & 10.0000 & 0.1000 \\ 0.800 & 0.0436 & 10.0000 & 10.0000 & 0.1000 \\ 0.900 & 0.0419 & 10.0000 & 10.0000 & 0.1000 \\ 1.000 & 0.0405 & 10.0000 & 10.0000 & 0.1000\end{array}$

Table 2-la. Errors due to voltmeter when RVG is used, $0.1-1 \mathrm{~mW}$.

$\begin{array}{lrrr}\text { P. min } & \text { ERROR, } 8 & \text { V1 RANGE } & \text { V2 RANGE } \\ 0.100 & 23.1772 & 10.0000 & 10.0000 \\ 0.200 & 11.5746 & 10.0000 & 10.0000 \\ 0.300 & 7.7071 & 10.0000 & 10.0000 \\ 0.400 & 5.7734 & 10.0000 & 10.0000 \\ 0.500 & 4.6131 & 10.0000 & 10.0000 \\ 0.600 & 3.8396 & 10.0000 & 10.0000 \\ 0.700 & 3.2871 & 10.0000 & 10.0000 \\ 0.800 & 2.8727 & 10.0000 & 10.0000 \\ 0.900 & 2.5504 & 10.0000 & 10.0000 \\ 1.000 & 2.2926 & 10.0000 & 10.0000\end{array}$

Table 2-1b. Errors due to voltmeter when no RVG is used, $0.1-1 \mathrm{~mW}$.

\begin{tabular}{|c|c|c|c|c|}
\hline P,mW & ERRCR, o & VI RANGE & V2 RANGE & V3 RANGE \\
\hline 1.000 & 0.0405 & 10.0000 & 10.0000 & 0.1000 \\
\hline 2.000 & 0.0341 & 10.0000 & 10.0000 & 0.1000 \\
\hline 3.000 & 0.0442 & 10.0000 & 10.0000 & 1.0000 \\
\hline 4.000 & 0.0400 & 10.0000 & 10.0000 & 1.0000 \\
\hline 5.000 & 0.0376 & 10.0000 & 10.0000 & 1.0000 \\
\hline $6.0 \mathrm{DO}$ & 0.0359 & 10.0000 & 10.0000 & 1.0000 \\
\hline 7.000 & 0.0348 & 10.0000 & 10.0000 & 1.0000 \\
\hline 8.000 & 0.0339 & 10.0000 & 10.0000 & 1.0000 \\
\hline 9.006 & 0.0333 & 10.0000 & 10.0000 & 1.0000 \\
\hline 10.006 & 0.0328 & 10.0000 & 10.0000 & 1.0000 \\
\hline
\end{tabular}

Table 2-1c. Errors due to voltmeter when RVG is used, 1-10 mW.

\begin{tabular}{|c|c|c|c|}
\hline P, min & ERROR, of & VI RANGE & V2 RANGE \\
\hline 1.000 & 2.2926 & 10.0000 & 10.0000 \\
\hline 2.060 & 1.1323 & 10.0000 & 10.0000 \\
\hline 3.000 & 0.7455 & 10.0000 & 10.0000 \\
\hline 4.000 & 0.5520 & 10.0000 & 10.0000 \\
\hline 5. 0uv & 0.4359 & 10.0000 & 10.0000 \\
\hline 6.000 & 0.3585 & 10.0000 & 10.0000 \\
\hline 7.000 & 0.3032 & 10.0000 & 10.0000 \\
\hline 8.000 & 0.2617 & 10.0000 & 10.0000 \\
\hline $9.00 v$ & 0.2294 & 10.0000 & 10.0000 \\
\hline 10.006 & 0.2635 & 10.0000 & 10.0000 \\
\hline
\end{tabular}

Table 2-1d. Errors due to voltmeter when no RVG is used, $1-10 \mathrm{~mW}$. 


\section{SECTION III \\ MAINTENANCE AND CALIBRATION}

\subsection{INTRODUCTION}

This section provides calibration and performance testing information. The adjustment procedure below assures that the unit will meet specifications. Failure of a unit is indicated by inadequate response to one or more of the adjustments, and further troubleshooting is required. This section also includes information on replacement of special components. All details refer to NBS-built units.

When it becomes necessary to remove a component from the two-sided printed circuit board, do so with great care. A solder removing tool must be used to remove solder from around the component leads. This will minimize the danger of lifting the circuit pattern from the board, a condition not easily repaired. Generally, for two-lead components, it is safer to remove the defective part by cutting the leads as close as possible to the body of the part. The replacement is then soldered to the leads of the old component.

\subsection{TEST EQUIPMENT}

The following test equipment is required:

1. DC null detector (microvoltmeter)

Range: \pm 10 microvolts fullscale to $\pm 30 \mathrm{~V}$ fullscale

Input impedance: 100 kohms or greater, resistive

Accuracy: $\pm 2 \%$ of fullscale

2. General purpose oscilloscope

3. DC milliammeter

Range: $30 \mathrm{~mA}$

Accuracy: $\pm 2 \%$

4. Standard resistor, 4-termina1, 100 ohms $\pm 0.01 \%$ or better. The accuracy of the power meter depends directly upon the accuracy of this resistor.

5. Thermistor mounts for $100 \mathrm{ohm}$ and $200 \mathrm{ohm}$ operation.

6. Pulse generator

Required output is $1 \mathrm{~ms}$ pulse, negative-going from $+5 \mathrm{~V}$ to ground.

Output impedance: 100 ohms or less

7. Adjustable resistance decade or 10-turn potentiometer, capable of adjustment over range of 0 to 100 ohms with $0.1 \%$ resolution. Accuracy is immaterial.

8. Diode, silicon, 1 N4153 or equivalent.

9. AC voltmeters for line-voltage tests, 105-130 V.

10. Adjustable autotransformer for line voltage test, $117 ; 105-130 \mathrm{~V}$.

11. Power supply, $+5 \mathrm{~V}, 25 \mathrm{~mA}$ minimum.

\subsection{INITIAL SETUP}

1. With the instrument turned off, remove the left side by removing 2 screws each from the front and rear panels.

2. Connect the links, if necessary, and connect the 1 N4153 diode between the BOLOM terminals, with the anode to the red terminal. Set the 100-REM-200 switch to 100.

3. Connect the instrument to the autotransformer, and set it for 105 volts. 
1

c 
4. Apply power, allow at least five minutes for warmup stabilization.

5. Set the GND-FLOAT switch on the rear panel to FLOAT. It should remain in that position throughout all adjustments. NOTE: The red ERROR lamp on the front panel should remain dark throughout the entire adjustment and calibration procedure, except for momentary indications when changing the setting of the 100-REM-200 switch. It is impossible to perform the adjustments if the lamp is 1it, and the cause must be found and corrected.

6. Check the jumpers for proper placement: brown to E1l, red to E2, green to E15, blue to E6, and gray to E8. The ribbon cable connector should be seated securely in $\mathrm{J} 101$.

\subsection{POWER SUPPLY PERFORMANCE (FIG. 3-1)}

1. There are two dual isolated supplies, each providing plus and minus $15 \mathrm{~V}$. They are designated supply "A" and supply "B". The common of the A supply is connected to the black BOLOM terminal. Measure the At output at E7 (gray jumper) while changing the line voltage from 105 to 130 volts. It should remain in the range 14.4 to $15.6 \mathrm{~V}$.

2. Repeat the measurement for the A- supply; this is accessible at the ase of ARI0l. The voltage should remain in the range -14.4 to $-15.6 \mathrm{~V}$.

3. Repeat the measurement for the Bt supply. The B supply comnon is connected to E5. The $\mathrm{Bt}$ is accessible at the collector tab of power transistor Q115. The range of voltage is 14.4 to 15.6 volts.

4. Repeat the measurement for the B- supply, which is accessible at the case of AR102. The voltage should remain in the range -14.4 to $-15.6 \mathrm{~V}$.

Any out-of-tolerance indications from the above tests indicate failure of one or more of the voltage regulators, filter capacitors, rectifiers, or transformer. Also, check for incorrect insertion of the line voltage selector card.

\subsection{AMPLIFIER OFFSET ADJUSTMENT (FIG. 3-3)}

The two operational amplifiers, AR101 and AR102, are provided with null balancing potentiometers. In making these adjustments, it is important that the amplifiers be in thermal equilibrium; heat from fingers, etc., must be allowed to dissipate before attempting a balance. In addition, the null detector used should be very well isolated from ground, preferably battery operated. The leads used with it should not exhibit large thermal emfs when handled. Proper operation of the instrument depends upon the cancellation of the emfs arising from dissimilar metals in the circuit, such as solder, copper, socket contact alloys, integrated circuit lead alloys, and so forth. This cancellation occurs only if there are no large temperature gradients across the circuit board; therefore, it is advisable to protect the unit from drafts and strong light sources with a loose cover after attaching the test leads. When a stable indication is obtained on the null detector, the adjustments may be made.

1. Connect the null detector between E11 and E2. It is essential that the measurement not be made between E1I and El, because El carries current, and an error will be introduced. Adjust R128 for a null. A stable indication of less than \pm 10 microvolts should be obtained.

2. Repeat for AR102 by connecting the null detector between E6 and E15 and adjusting R140.

Failure to obtain a proper null may be due to defective AR101 or AR102, or to any condition which prevents the servo from balancing, as indicated by the ERROR lamp. 


\subsection{CURRENT INDICATOR (FIG, 3-3)}

The front panel milliammeter serves only to indicate the approximate bolometer current; it is not intended to be used for measurement. It is adjusted as follows:

1. Turn off the power.

2. Remove one end of the diode across the BoLOM terminals and insert in series both the 0 to $100 \mathrm{ohm}$ adjustable resistor and the dc milliammeter against which the adjustment is to be made. Set the 100-REM-200 switch to 100 . Turn the power on.

3. If the ERROR lamp is lit, reduce the value of the series resistor. It should be possible to obtain an indication of $30 \mathrm{~mA}$ on the external meter by adjustment of the resistor. Increasing the resistance increases the current, because in order to maintain the series combination of diode, resistor, and external meter constant at $100 \mathrm{ohms}$, the servo must decrease the apparent resistance of the diode by increasing the current through it. Use of the diode eliminates the danger of damage to a valuable thermistor mount during this procedure.

4. After obtaining a current of $30 \mathrm{~mA}$ on the external meter, adjust R143 to bring the internal meter to full scale indication. Turn off power.

\subsection{CALIBRATION OF INTERNAL RESISTORS (FIG. $3-3 \& 3-4$ )}

The absolute accuracy of the instrument depends upon the accuracy of the resistance against which the thermistor is compared by the servo. This resistance is composed of two adjustable resistances, connected in such a way that separate potential and current leads are available both ends and at the junction of the two resistances. This makes it possible to define ch of them (very accurately), without concern for the resistance of the circuit board pattern. The adjustment procedure is based upon the comparison technique shown in the Appendix, Figure 2. Section 3.5 must be completed before the following steps are undertaken:

1. Turn the power off. Remove AR101. Transfer the gray jumper from E8 to E9. Set the 100-REM-200 switch to 100 .

2. Open the links. Attach the $100 \mathrm{ohm}$ standard resistor to the front panel terminals. The current terminals must be connected to the BOLOM binding posts of the instrument, and the potential terminals must be connected to the respective blue SENSE binding posts.

3. Turn the power on and allow at least 5 minutes for stabilization.

4. Attach the null detector between E1l and E2.

At this point, in accordance with the discussion in Appendix I, current is flowing through Q109 into E3, the junction of the two resistors. This current is now fixed, limited by R144A to about $16 \mathrm{~mA}$. The null detector is reading what would be the input signal to ARI0l. If the internal resistor comprised of R133-R136 is not identical to the external standard, the difference in the voltage drops across the two will appear on the null detector. The sensitivity of the measurement is about 1.6 parts per million per microvolt. Since no current flows through $\mathrm{R} 129-\mathrm{R} 132$, the detector is connected to $\mathrm{E} 2$ for convenience.

5. Adjust R135 for a null indication on the null detector. A null of less than 10 microvolts should be obtained.

6. Turn the power off. Transfer the blue jumper from E6 to E4. Set the 100-REM-200 switch to 200 . Turn the power on.

rent is now flowing through al1 of R129-R136, but AR102 is now sensing the potential at

instead of E6. Therefore, R133-R136 are now outside of the loop, as far as the calibration is concerned. 
7. Adjust R131 for a null of less than 10 microvolts.

8. Turn the power off. Replace AR101. Return blue jumper to E6. Return gray jumper to E8. Remove external standard.

Inability to make the above adjustments indicates failure of AR102, misadjustment of amplifier offset, failure of Q109 or Q112, or out-of-tolerance resistors in the network R129-R136. The adjustment range of each half of the resistor network comprising R129-R136 is $\pm 0.05 \%$ around the nominal $100 \mathrm{ohm}$ value. The nominal tolerance on the principal resistors, R130 and $R 134$, is $\pm 0.01 \%$, so that it is unlikely that they will ever drift so far that adjustment is impossible. Worst-case accumulation of limit tolerance resistors will still allow proper adjustment. The precision of the adjustment, limited by the setability of the trimmers, is about $\frac{1}{4} \mathrm{ppm}$. Because of the 4-terminal connection to the external standard, lead resistances of as much as 1 ohm produce no detectable error.

If trouble is suspected, certain checks may isolate the cause. When the instrument is operating with a thermistor or diode, measure the voltage between E2 and E4 in the 100 ohm condition with a null detector. It should be essentially zero, less than 10 microvolts. A higher value indicates failure of Q112 to turn off. A similar test can be applied to Q109, by interchange. These transistors are MOS field effect devices with no gate protection diodes, so they may be easily damaged by static discharge. Do not allow them to contact polyethylene or polystyrene sheet or foam. Transistors Q114 and Q113 connect the red DVM terminal to the appropriate point, depending upon the setting of the 100-REM-200 switch. If either has excessive leakage in the off state, errors will result.

\subsection{GAIN AND NOISE TESTS}

The error analysis of the servo is based on a model which assumes that the amplifier differential input voltages never exceed a certain value under any condition of operation, including temperature effects and finite amplifier gain. The resulting equation is given in Appendix I equation (1). In order to ensure that the instrument is actually performing to specifications, it is necessary to measure the amplifier gains.

1. Set up the instrument as described in Section 2.2, preferably with a 100 ohm thermistor mount.

2. Connect the null detector between E11 and E2. If offset adjustment, Section 3.5 has been carried out properly, this reading should be less than 10 microvolts. Record this reading.

3. Record the reading of the external voltmeter.

4. Apply rf power to the point where the external voltmeter reading has been reduced to about 0.2 volts. Record the readings of both the null detector and the voltmeter.

5. Connect the null detector between E6 and E15. Repeat steps 1-4 above.

The gain of each amplifier is found by dividing the change in the external voltmeter reading by the change in the null detector reading when rf power is applied. The amplifiers used in the Type IV have a minimum gain specification of 120,000 . The value will typically be larger than this. An amplifier showing a gain of less than this should be replaced and Section 3.5 should be repeated for that amplifier.

At low power levels, noise ultimately limits the usefulness of the instrument. The servo noise may be observed by connecting an oscilloscope to the DVM terminals with a diode across the BOLOM terminals, anode to the red terminal. The trace should show no "flicker" or "popcorn" noise--only a steady display of about $1 \mathrm{mV}$ peak-to-peak amplitude. There should be no components present which are synchronous with the line frequency. A true-rms wideband voltmeter connected across the DVM terminals should indicate not more than 100 microvolts in a band from $10 \mathrm{~Hz}$ to $10 \mathrm{MHz}$. 

noise measurements are made with a thermistor, the noise due to a defective component is likely to be obscured by the excess noise generated by the thermistor bead itself. On the other hand, the diode is not a good dynamic simulation of the thermistor, because it has a virtually zero response time. Therefore, it is also informative to examine the noise with a typical mount. When this is done, line-synchronous noise will usually be seen. This is due to magnetic field leakage from the power transformer coupling with the printed circuit board pattern. Because the bandwidth of the servo is now limited by the thermistor, it cannot maintain balance for these disturbances (mostly $120 \mathrm{~Hz}$ and higher line harmonics). However, measurement accuracy will not be affected with most voltmeters because of the very high linefrequency rejection inherent in their design. Typical amplitudes are on the order of $3 \mathrm{mV}$ peak-to-peak. The noise will now also show flicker characteristics. There is considerable variation in excess noise from one thermistor to the next.

\subsection{TEST OF INTERFACE LOGIC (FIG. 3-2)}

The Type IV power Meter is provided with circuitry to allow change of mount operating resistance by an external controller, and to give indication of certain kinds of malfunction to the controller. The interface is simple; most of the timing and "handshaking" circuitry must be provided by the system controller. Since it must be possible to FLOAT the unit, optoisolators are used for all digital signals in and out.

1. Turn the power off. It is necessary to provide 1 kohm pullup resistors for P101, pins 7, 9, and 10, in order to give an observable signal. Connect three resistors between these pins and P101-2. Connect the $+5 \mathrm{~V}$ supply to P101-2 also. Connect the negative side of the supply to P101-5.

2. Connect a diode to the Bolom terminals, anode to red terminal. Turn the power on. Set 100-REM-200 to REM.

Apply a negative pulse to P101-1, from $+5 \mathrm{~V}$ to $0 \mathrm{~V}$. The 200-ohm indicator should light and stay lit after the pulse is removed.

4. Apply the negative pulse to P101-3. The 100 indicator should light and stay lit after the pulse is removed.

If the thermistor mount is used in place of a diode, the ERROR lamp will flash momentarily during the transition from the $100 \mathrm{ohm}$ state to the $200 \mathrm{ohm}$ state, or vice versa. This is due to the time lag occasioned by the thermal capacity of the thermistor bead. When going from $200 \mathrm{ohms}$ to $100 \mathrm{ohms,}$ the lag is short because of the ability of the instrument to supply additional current rapidly; the temperature rise is also rapid. On the other hand, when cooling from $100 \mathrm{ohms}$ to $200 \mathrm{ohms,}$ the cooling rate is dependent solely on the mount characteristics and is determined mostly by the conduction of heat from the bead along its leads. Therefore, the ERROR light will stay on for a large part of a second. This is normal.

5. Monitor P101-9 with the oscilloscope while applying pulses to first Pl01-1 and then P101-2. A negative-going $+5 \mathrm{~V}$ to $0 \mathrm{~V}$ pulse should appear at P101-9 following every positive-going transition of the test pulse. The presence of this pulse confirms that the instrument has received the test pulse.

6. Apply the test pulse to P101-1 and P101-2 simultaneously. No response pulse should be seen at P101-9. This ensures that ambiguous commands do not produce an acknowledging pulse at P101-9.

7. Monitor Pl01-10. When the test pulse is applied to Pl01-1, no pulse should appear at P101-10. When the test pulse is applied to P101-2, a negative-going $+5 \mathrm{~V}$ to $0 \mathrm{~V}$ pulse should appear at P101-10. This pulse provides information on the state to which the instrument has been set: it appears only when set to 100 ohms. If present, it is coincident with the pulse appearing at pl01-9.

Monitor Pl0l-7. This pin goes low whenever an out-of-balance condition occurs in the servo. This should occur after every transition from 100 to 200 ohms, or vice versa, but at no other time. This pulse may be difficult to observe unless a thermistor mount is used instead of a diode. Short the diode or thermistor mount. P101-7 should go low. This tells the system that data taken while P101-7 is low is invalid, and that a fault condition exists, such as open or shorted bolometer leads, or rf overload. 


\subsection{NONSTANDARD COMPONENTS}

Use of unusual or nonstandard components has been kept to a minimum; however, certain components must meet critical specifications. These are:

1. R130 and R134, 100 ohms $\pm 0.01 \%$, wirewound, specifled at $23^{\circ} \mathrm{C}$ and negligible power. Drift: $\pm 50 \mathrm{ppm} / \mathrm{yr}$ Temperature coefficient: $\pm 5 \mathrm{ppm} /{ }^{\circ} \mathrm{C}$ Temperature rise (power coefficient): less than $25^{\circ} \mathrm{C}$ rise per watt.

2. T201, power transformer. The primary is split for $117 / 234$ volt operation. One primary is tapped for 100 volt operation; this partial winding must be able to carry the entire burden with a 100 volt supply line. Secondaries are split and shielded, 36 volts center tapped, $90 \mathrm{~mA}$ per winding to fullwave rectifier. The critical specification is for interwinding capacitance. Three-terminal capacitance between primary and either secondary, or between secondaries must be less than 0.01 picofarad with all shields grounded.

3. AT101-AT105 optoisolators. While these are not critical in the same sense as the two components mentioned above, it is desirable that the current transfer ratio be adequate to allow direct interfacting with TTL logic, while maintaining a collector swing meeting the usual $0.8 \mathrm{~V}$ low and $2.4 \mathrm{~V}$ high logic levels. Common Darlington optoisolators may not meet the $0.8 \mathrm{~V}$ specification.

The specific components selected for the prototype instruments were chosen on the basis of suitability, availability, and cost and do not represent the only possible choices. The National Bureau of Standards does not represent that they are the best possible for the application, only that they were used in the instruments described here. Substitution of nominally equivalent components meeting the same specifications should normally cause no difficulty; however, the National Bureau of Standards has not tested all such possible choices. In case of question, please consult with the designer. 


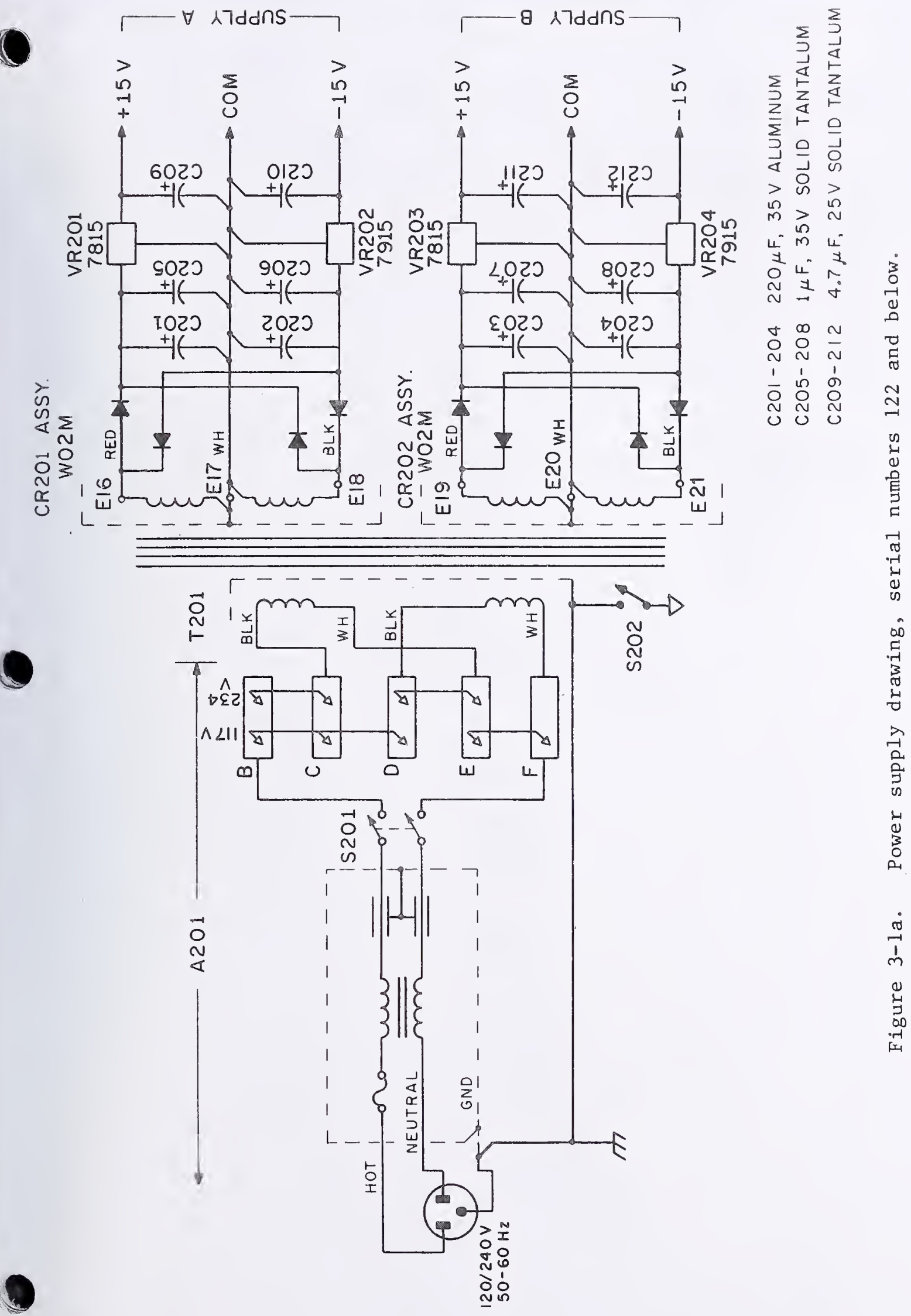


C 


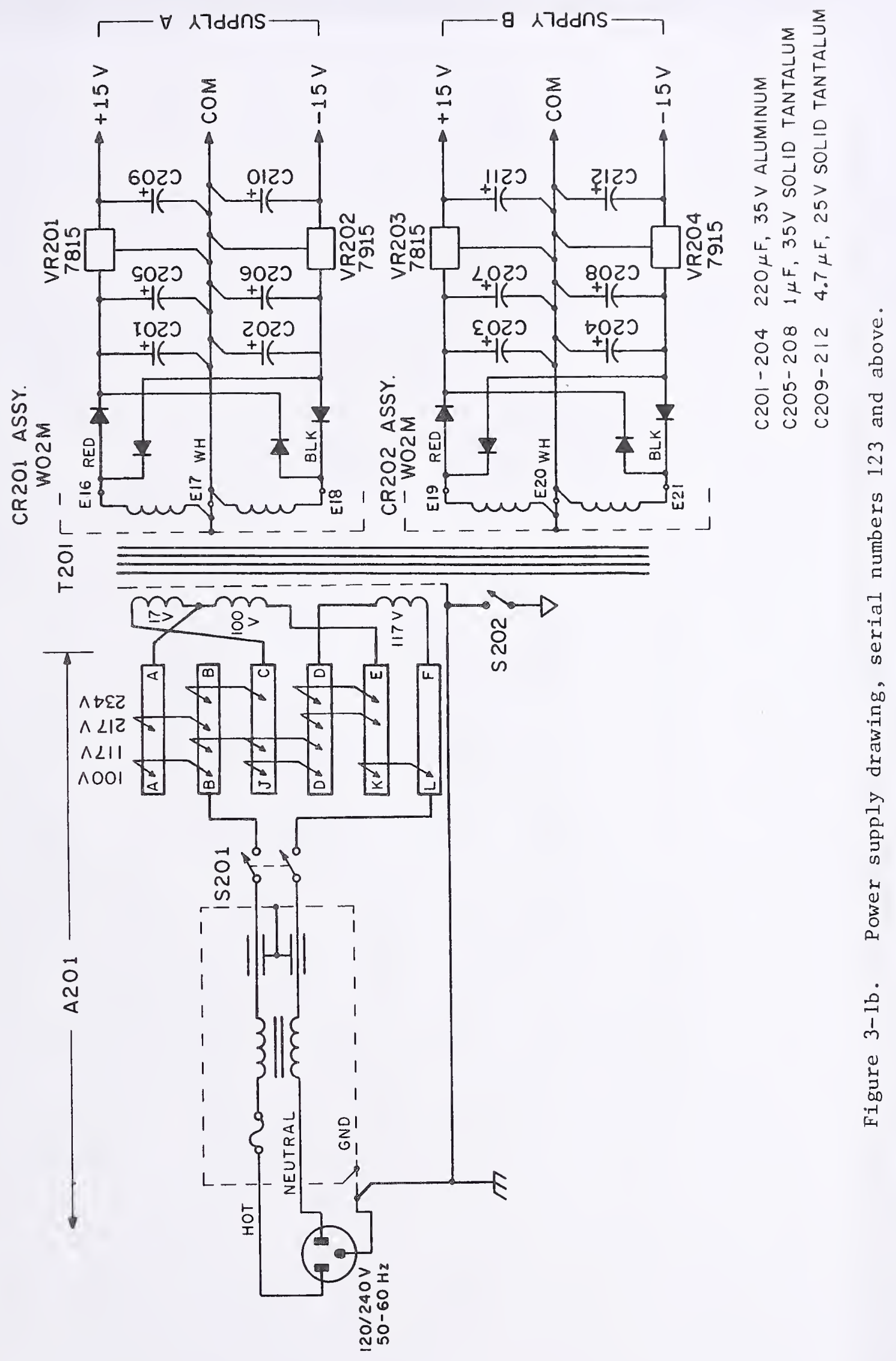




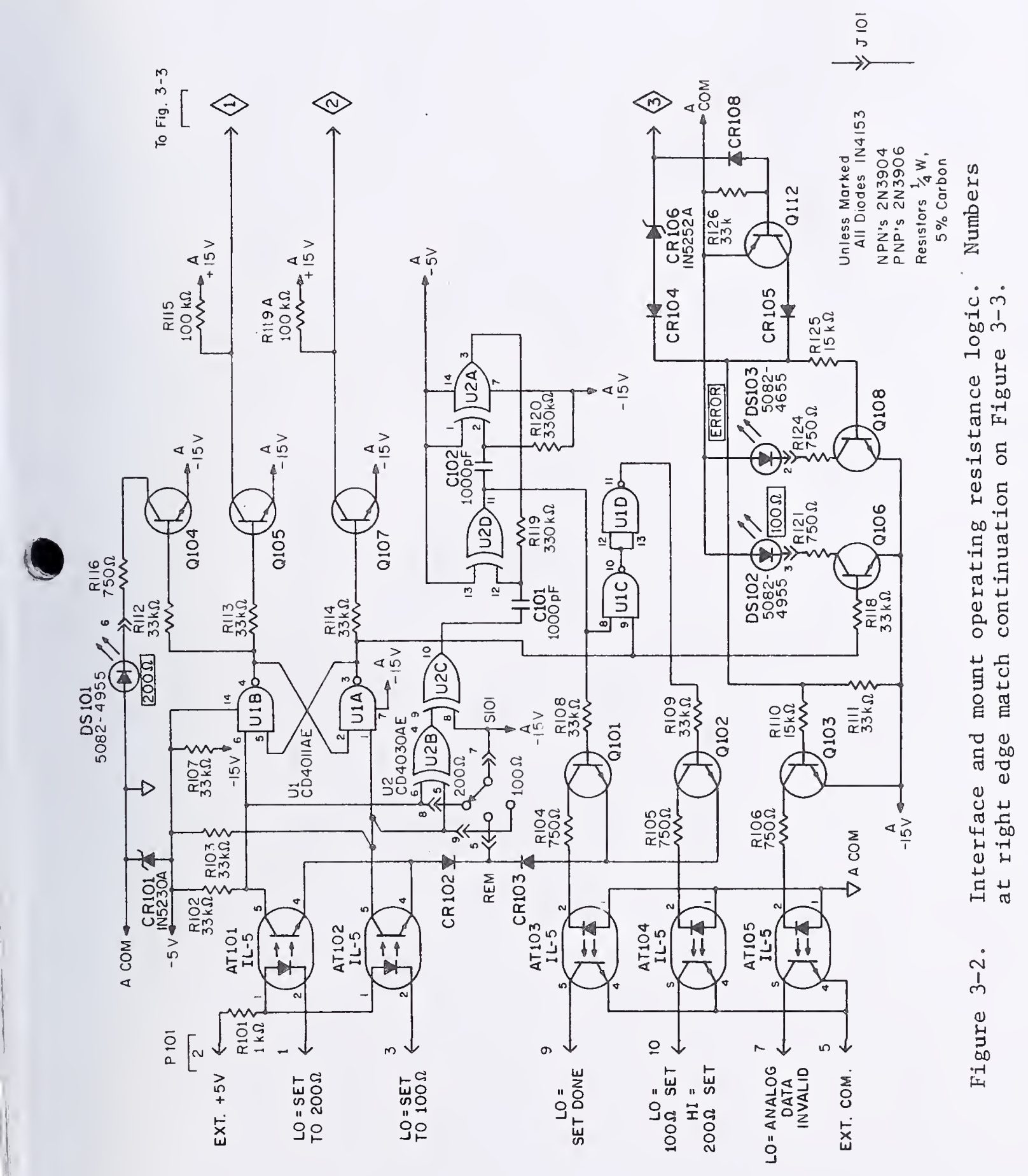


C 


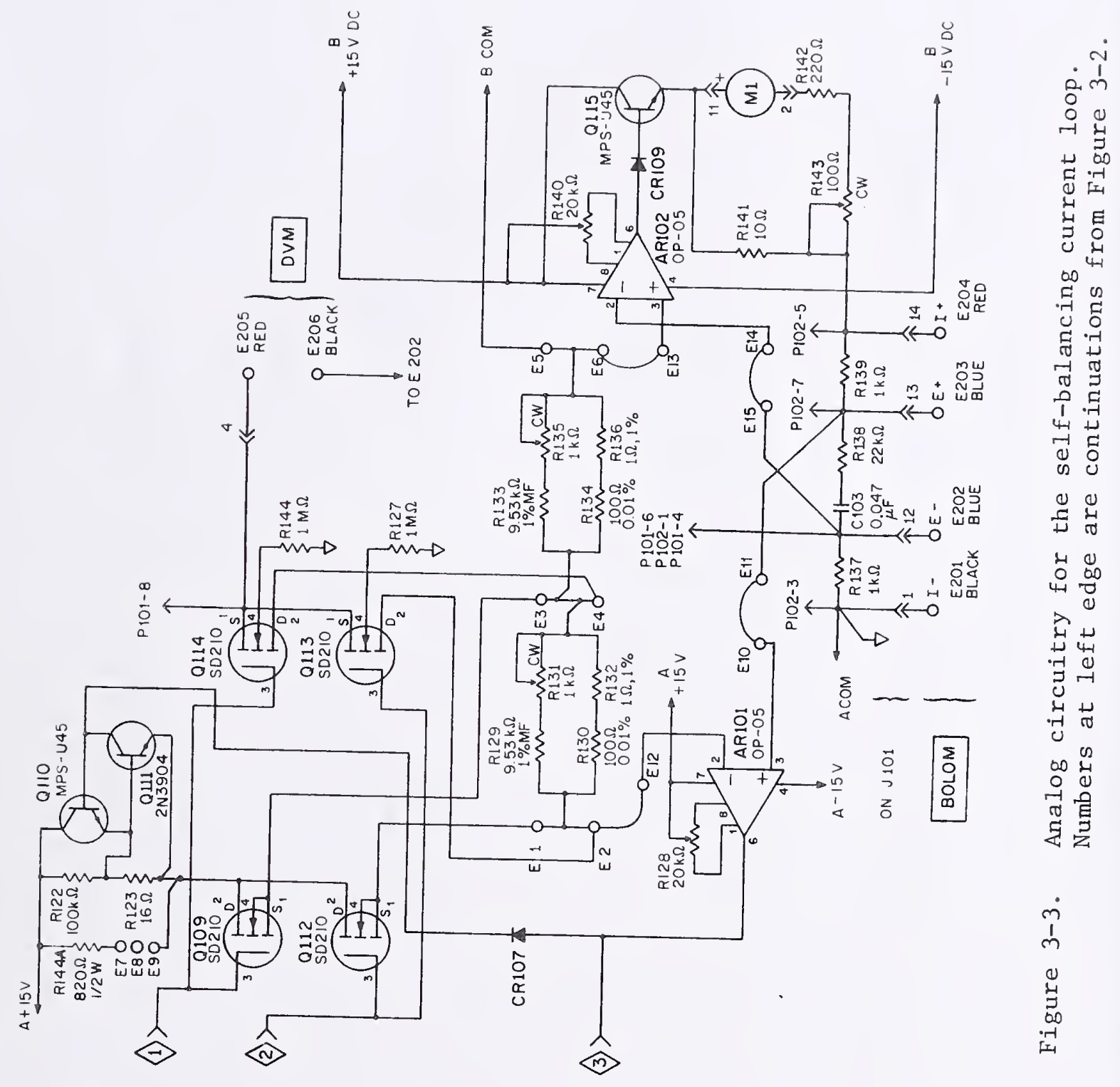




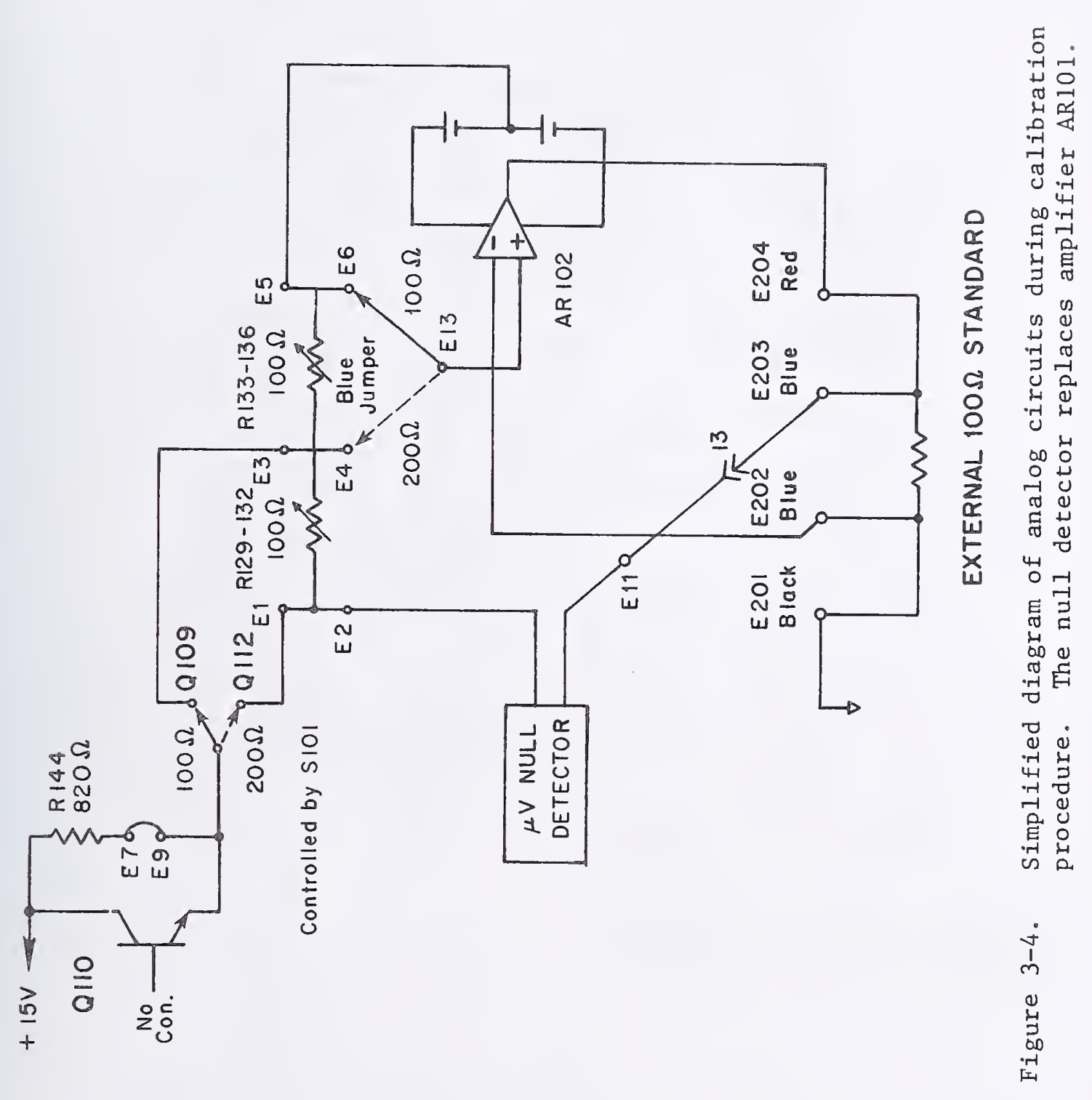


K 


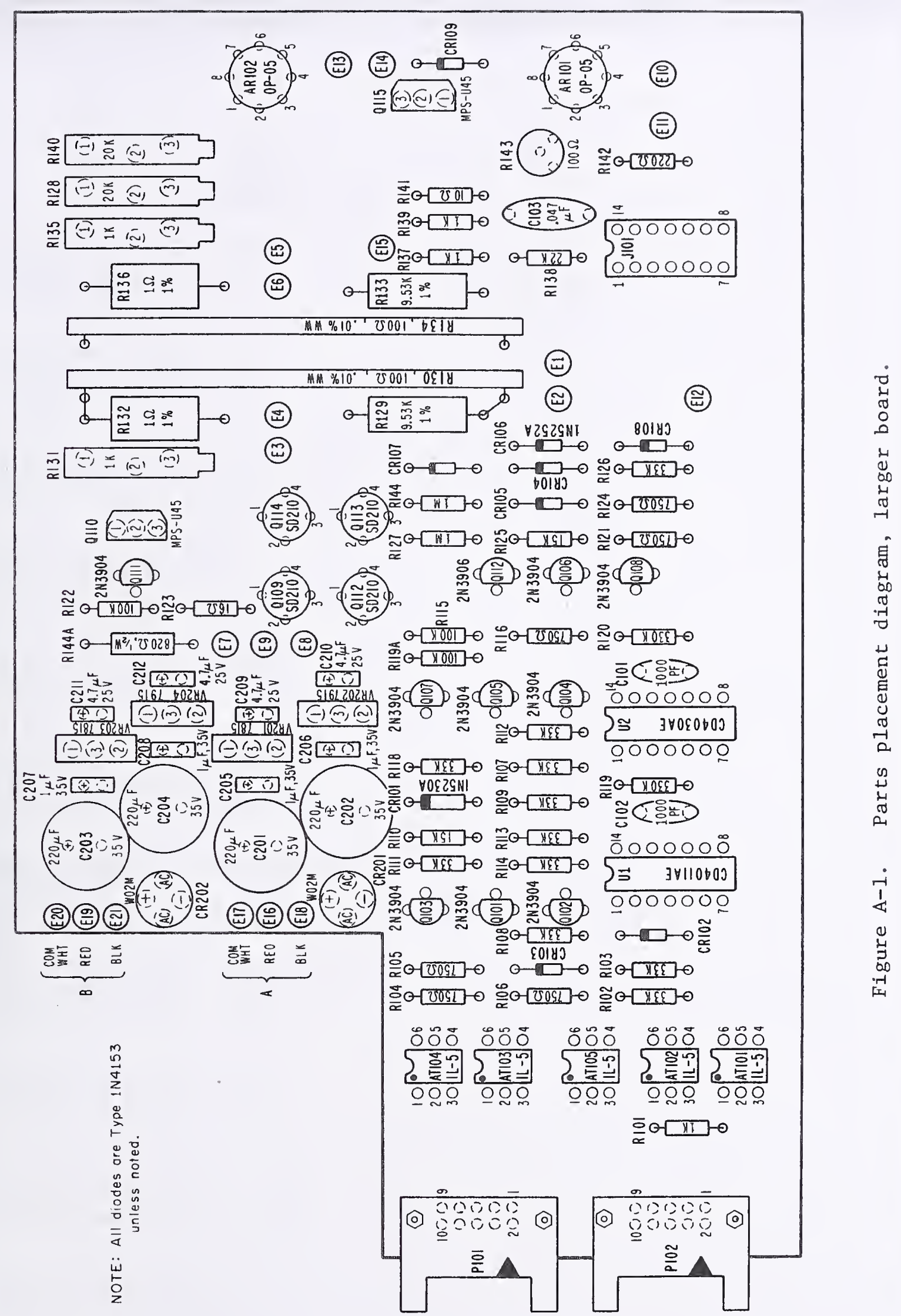


C 
TABLE $A-1$

MANUFACTURER'S CODES

$3 M$

3M Company, Electronic Products Division

3M Center

St. Paul, Minnesota 55101

$\mathrm{AB}$

Allen-Bradley Company

1201 S. Second Street

Milwaukee, Wisconsin 53204

ALCO

Alcoswitch Division of Alco Electronic Products, Inc.

P. O. Box 1348

Lawrence, Massachusetts 01842

AMPH

Bunker Ramo Sales Division

2875 South 25th Street

Broadview, Illinois 60153

API

LFE Corporation, Process Control Division

1601 Trapelo Road

Waltham, Massachusetts 02154

AZTE

Aztec Electronics, Incorporated

1240 Blue Gum Street

Ananeim, Cal ifornia 92806

BELD

Belden Corporation, Electronic Division

P. O. Box 1331

Richmond, Indiana 47374

BOUR

Bourns, Incorporated, Trimpot Division

1200 Columbia Avenue

Riverside, California 92507

CA

Circuit Assembly Corporation

3169 Red Hill Avenue

Costa Mesa, California 92626

CAMB

Cambridge Thermionic Corporation

445 Concord Avenue

Cambridge, Massachusetts 02138

CORC

Corcom, Incorporated

2635 North Kildare Avenue

Chicago, Illinois 60639

CORN

Corning Glass Works, Electronic Products Division Houghton Park, Bldg. A-2

Corning, New York 14830 
L 
TABLE A-1

MANUFACTURER'S CODES, CONTINUED

DALE

Dale Electronics, Incorporated

Box 609

Columbus, Nebraska 68601

DEST

Destek Industries

P. O. Box 24163

Los Angeles, California 90024

ELCO

ELCO

Maryland Road \& Computer Avenue

Willow Grove, Pennsylvania 19090

ERIE

Erie Technological Products

644 West 12 th Street

Erie, Pennsylvania 16512

ESI

Electro Scientific Industries

13900 N.W. Science Park Drive

Portland, Oregon 97229

GE

General Electric Co., Semiconductor Products Department

Electronics Park, Box 1122

Syracuse, New York 13201

GENE

General Instrument Corp., Semiconductor Products Division 600 West John Street

Hicksville, New York 11802

HHSM

Herman H. Smith, Incorporated

812 Snediker Avenue

Brooklyn, New York 11207

HP

Hewlett-Packard, Optoelectronic Division

640 Page Mill Road

Palo Alto, California 94304

JBT

$\mathrm{J}-\mathrm{B}-\mathrm{T}$ Instruments, Incorporated

Box 1904

New Haven, Connecticut 06509

KEME

Union Carbide Corporation, Components Department

Box 5928

Greenville, South Carolina 29606

KODA

Eastman Kodak Company

343 State Street

Rochestor, New York 14650 


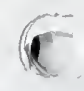


TABLE A-1

MANUEACTURER'S CODES, CONTINUED

LITR

Litronix, Incorporated

19000 Homestead Road

Cupertino, California 95014

MOTO

Motorola Semiconductor Products

2002 West 10th Place

Tempe, Arizona 85281

PMI

Precision Monolithics, Incorporated

1500 Space Drive

Santa Clara, California 95050

$\mathrm{RCA}$

RCA Sol id State Division

Route 202

Somerville, New Jersey 08876

SCHA

IEE/Schadow, Incorporated

8081 Wallace Road

Eaen Prairie, Minnesota 55343

SIGN

Signetics Corporation

811 East Arques Avenue

Sunnyvale, California 94986

SPRA

Sprague Electric Company

481 Marshall Street

North Adans, Massachusetts

SUPR

Superior Electric Company

1000 Middle Street

Briston, Connecticut $\emptyset 6010$

THER

Thermalloy, Incorporated

2021 west Valley view

Dalıas, Texas 75234

ULTR

Ultronix, Incorporated

P. O. Box 1090

Grand Junction, Colorado 81501

USEC

USECO Division, Litton Industries

13536 Saticoy Street

van Nuys, California 91409 
C 
TABLE A-2

PARTS LIST

CATEOORY NO.

1 Rl01 3 CARBON, $0.25 w, 58$

2 Rl02 11 CARBON, $0.25 W_{*} 58$

3 R103 SAME AS R102

4 Rlø4 6 CARBON, $0.25 W, 5 \%$

5 R105

6 Rl06

7 Rl0 7

8 R108

9 Rl09

10 RI10

11 RIII

12 R112

$13 \mathrm{R} 113$

14 R114

15 R115

16 R116

17 Rl18

18 Rl19

19 R119A

20 R120

21 R121

22 R122

$23 \mathrm{R} 123$

24 R124

25 R125

26 R126

27 R127

28 R128

29 R129

30 R130

31 R131

32 R132

33 R133

34 R134

35 R135

$36 \mathrm{R} 136$

37 R137

38 Rl38

39 R139

$49 \mathrm{Rl} 40$

$41 \mathrm{R} 141$

42 RI42

43 R143

44 R144

45 RI44A
SAME AS R104

SAME AS RIO 4

SAME AS R102

SAME AS R102

SAME AS R102

2 CARBON, $0.25 \%, 5 \%$

SAME AS R102

SAME AS R102

SAME AS R102

SAME AS R10 2

3 CARBON, $0.25 \mathrm{~W}, 5 \%$ SAME AS RIO4

SAME AS R102

2 CARBON, $0.25 \mathrm{~W}, 5 \%$ SAME AS R115

SAME AS R119

SAME AS R104

SAME AS R125

1 CARBON, $0.25 \mathrm{~W}, 58$

SAME AS R10 4

SAME AS RII0

SAME AS R102

2 CARBON, $0.25 \mathrm{~W}, 58$

2 TRIMMER, METAL FILM

2 METAL FILM, $0.125 \mathrm{~W}, 18$

2 WIRENOUND, 0.018

2 TRIMMER, MELAL FILM

2 WIREWOUND, $1 \%, 0.15 \mathrm{~W}$ SAME AS R129

SAME AS R130

SAME AS R131

SAME AS R132

SAME AS RIOI

1 CARBON, $0.25 W, 5$ \%

SAME AS R101

SAME AS R128

1 CARBON, $0.25 W, 5 \%$

1 CARBON, $0.25 \mathrm{~W}, 58$

1 TRIMMER, METAL FILM SAME AS R127

1 CARBON, $0.5 \%, 58$
1000 OHMS $A B$

33 KOHMS $A B$

750 OHMS AB

FSN 5905-681-6462

FSN 5905-577-9602

FSN $5905-807-4954$

15 KOHMS $A B$

FSN 5905-681-8818

100 KOHMS AB

FSN 5905-686-3129

330 KOHMS $A B$

FSN 5905-686-3131

16 OHMS

$A B$

FSN 5905-835-1630

1 MOHM

20 KOHM

9530 OHMS

100 OHMS

$1 \mathrm{KOHM}$

$1 \mathrm{OHM}$

$A B$

BOUR

CORN

ESI

BOUR

DALE

3009P-1-102

RB55CEIRO0øF
RF6R

FSN 5905-681-8817

3009P-1-203

F6 $\mathrm{R}$

CATEGORY NO.

$\begin{array}{ll}1 & \mathrm{Cl} 101 \\ 2 & \mathrm{Cl02} \\ 3 & \mathrm{C} 103 \\ 4 & \mathrm{C} 201 \\ 5 & \mathrm{C} 202 \\ 6 & \mathrm{C} 203 \\ 7 & \mathrm{C} 204\end{array}$

2 DISC CERAMIC, IKV SAME AS CIOl

1 METALLIZED FILM, 100V

4. ALUM INUM, 35V

SAME AS C201

SAME AS C2øl

SAME AS C201

22 KOHMS $A B$

10 OHMS

220 OHMS

100 OtMS

820 OtMS 
6

1

( 
TABLE A-2

PARTS LIST, CONTINUED

$8 \mathrm{C} 205$

$9 \mathrm{C} 206$

$10 \mathrm{C} 207$

$11 \mathrm{C} 208$

12 C209

$13 \mathrm{C} 210$

14 C211

$15 \mathrm{C} 212$
4 SOLID TANTALUM, 35V SAME AS C205

SAME AS C 205

SAME AS C205

4 SOLID TANTALUM, 25V

SAME AS C209

SAME AS C209

SAME AS C209
$1 \mathrm{MF}$

KEME T330A105K035AS

4.7 MF KEME T330A475K025AS

CATEGURY NO.

-TRANSISTORS

1 Q101 9 SILICON NPN

2 Q102 SAME AS Q101

2N3994 MOTO FSN 5961-892-8706

$3 \mathrm{Q103}$

$4 \mathrm{Q} 104$

5 Q105

$6 \mathrm{Q} 106$

70107

80108

9 Q109

$10 \quad 2110$

11 Q111

$12 \mathrm{Q} 112$

13 Q112A

140113

150114

$16 \mathrm{Q} 115$

SAME AS Q101

SAME AS Q10I

SAME AS 0101

SAME AS Q101

SAME AS Q101

SAME AS O101

4 MOSFET, N-CHANNEL SD210 SIGN

2 SILICON NPN DARLINGION MPS-U45 MOTO SAME AS Q101

SAME AS Q109

1 SILICON PNP

SAME AS Q109

SAME AS Q109

SAME AS Q110

2N3906 MOTO FSN 5961-931-0372

CATEGORY NO.

$1 \mathrm{CR} 101$

2 CRIO2

3 CRIO 3

4 CRIO 4

5 CRIV5

6 CRID 6

7 CRI07

8 CRI08

9 CRIg9

$10 \mathrm{CR} 201$

$11 \mathrm{CR} 202$

12 DSI01

13 DS102

14 DSI03
1 ZENER, 4. $N, 10 \%, 0.5 \mathrm{~W}$

7 SILICON SIGNAL SAME AS CRIO2

SAME AS CRIO2

SAME AS CRIV2

1 ZENER, 24V, 10\%, 0.5W IN5252A MOTO

SAME AS CRIV 2

SAME AS CRIO2

SAME AS CRIO2

2 RECTIFIER, FW BRIDGE WO2M

SAME AS CR2U1

2 LED, GREEN

SAME AS DS 101

1 LED, RED
IN5230A MOTO

IN4153 GE

WO2M GENE

HP $\quad 5082-4955$

HP $\quad 5082-4655$

CATEGORY NO. 5-----------INTEGRATED CIRCUITS
1 ARIOI
( SAME AS AR101
2 ARI02
4 AT102
5 AT 103
6 AT104
7 AT 105
$8 \mathrm{Ul}$
5 OPTO-ISOLATOR
SAME AS ATIOI
$\mathrm{OP}-05 \mathrm{CJ} \quad \mathrm{PMI}$
IL-5 LITR
SAME AS AT101
SAME AS ATI0]
SAME AS ATIDI
1 CMOS, QUAD 2-INPUT NAND CDAOIIAE RCA 
C

1 
TABLE $A-2$

PARTS LIST, CONTINUED

$\begin{array}{llllll}9 & \text { U2 } & 1 \text { CMOS, QUAD EX-OR } & \text { CD4030AE } & \text { RCA } \\ 10 \text { VR201 } & 2 \text { VOLTAGE REGULATOR, 15V } & \text { MC7815C } & \text { MOTO } \\ 11 \text { VR202 } & 2 \text { VOLTAGE REGULATOR, -15V } & \text { MC7915C } & \text { MOTO } \\ 12 \text { VR203 } & \text { SAME AS VR201 } & & & \\ 13 \text { VR204 } & \text { SAME AS VR292 } & & & \end{array}$

CATEGORY NO.

$\begin{array}{ll}1 \\ 2 \\ 3 & \\ 4 & \\ 5 & \text { J101 } \\ 6 & \text { NONE } \\ 7 & \text { NONE } \\ 8 & \text { PlOI } \\ 9 & \text { PlO2 }\end{array}$

2 8-PIN PTFE SOCKET

5 6-PIN DIP SOCKET

2 14-PIN DIP TERMINATION

4 4-PIN PTFE SOCKET

3 14-PIN DIP SOCKET

2 MATE TO P101, $\mathrm{PlO} 2$ SAME AS JIOl

210 PIN MALE SCOTCHFLEX SAME AS PIOl

CONNECTORS-

CATEGORY NO.

1 El-15 10 PC VERTICAL HERMAPHRO

2 El-15 5 CRIMP HERMAPHRO

3 E20 2 BINDING POST, BLACK

4 E202 2 BINDING POST, BLUE

$5 \mathrm{E} 203$ SAME AS E202

6 E29 42 BINDING POST, RED

7 E205 SAME AS E204

8 E206 SAME AS E201

9 E16-21 6 TERMINAL, FORK, STAKED
AMPH $63126011 \quad 082$

САМВ 703-3771-01-03-16

3M 3406-1000

AMPH $63126011 \quad 942$

CA CA-14LSI-10SD

3M 3473-3000

3M 3491-1002

CATEGORY NO.

$1 \mathrm{~s} 101$

$2 \mathrm{~S} 201$

$3 \mathrm{~S} 202$
1 SP3'T SLIDE
1 2PDT PUSH-PUSH
1 SPDT 'TOGGLE

ELCO 62-5201-02-13-90-011

ELCO $00-60-8017-0313$

SUPR DE2lBC

SUPR DF2lBLC

SUPR DE2IRC

USEC 2001BI

CATEGORY NO.

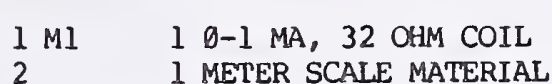

ALCO MSS-1300

SCHA ZFEA200BLK/GR2UNEI5

JBT JMT 123
CATEGORY NO. 10

$\begin{array}{ll}1 & 6 \text { SPACER, HEX BRASS } \\ 2 & 1 \text { CHASSIS AND PANELS } \\ 3 & 6 \text { MACHINE SCREWS } \\ 4 & 6 \text { WASHERS } \\ 5 & 2 \text { SWING LUGS, GOLDPLATED } \\ 6 & 1 \text { STOP, } 1 X 4.5 \times 9.962 \text { IN }\end{array}$

METERS

API 1015-0003-0000

KODA CAT. NO. 1578285
HARDWARE

$$
\begin{aligned}
& \text { 6-32X0.25 HHSM } 2320 \text { (GOLD FLASH ADDED) } \\
& \text { 6-32×3/16 DEST K-33-9 (NO OPTIONS) } \\
& \text { \#6 SMALL } \\
& \text { 6061-T6 }
\end{aligned}
$$


6

6

I 
TABLE A-2

PARTS LIST, CONTINUED

CATECORIES 11 AND 12 ARE EMPIY.

CATEGORY NO. 13

-MISCELLANEOUS

\begin{tabular}{|c|c|c|c|c|}
\hline 1 & 1 LINE CORD & & BELD & 17250 \\
\hline 2 & WIRE。 PRIMARY POWER & 2-\#24 AiNG & BELD & 8461 \\
\hline 3 A201 & 1 LINE CONNECTOR/SELECTOR & & CORC & $6 J 4$ \\
\hline $4 \mathrm{~T} 201$ & 1 TRANSFOPMER, POWER & $117 / 36 / 36$ & AZTE & 13575 (SER $122 \&$ BELOW) \\
\hline $\begin{array}{ll}5 & \mathrm{~T} 201 \\
6 & \end{array}$ & $\begin{array}{l}1 \text { TRANSFOPMER, POWER } \\
4 \text { MOUNIING PAD, C201-C204 }\end{array}$ & $117 / 36 / 36$ & $\begin{array}{l}\text { AZTE } \\
\text { THER }\end{array}$ & $\begin{array}{l}13886 \text { (SER } 123 \& \text { ABOVE) } \\
7717-204\end{array}$ \\
\hline
\end{tabular}

TABLE $A-3$

CONNECTOR PIN ASSIGNMENTS

Pull low to set mount operating resistance to 200 ohms.

External +5 volt power for optoisolators. Drain is less than $5 \mathrm{~mA}$.

pull low to set mount operating resistance to $100 \mathrm{ohms}$.

Not used.

External common.

-DVM: Bolometer negative sense lead, black front panel DVM post E266 (also E202).

Goes low on any error condition; data is invalid when pin 7 is low.

+DVM: Red front panel DVM post E206.

Goes low to acknowledge completion of setting mount operating resistance (approximately 1 millisecond pulse, +5 volts to $\emptyset$ and back to +5 volts.

10

Cneck signal to acknowledge that specified mount operating resistance was set.

If mount was set to 100 ohms, a pulse identical to and coincident with the pulse

on pin 9 appears. If the mount was set to 200 ohms, no pulse appears.

P102:

Bolometer negative sense lead, in parallel with front panel blue post E202.

Not used.

Bolometer negative current lead, in parallel with front panel black post E20l.

Same as pin 1, P102.

Bolometer positive current lead, in parallel with front panel red post E204. Not used.

Bolometer positive sense lead, in parallel with front panel blue post E203.

Not used.

Not used.

10 Not used. 


\title{
A New Self-Balancing DC-Substitution RF Power Meter
}

\author{
NEIL T. LARSEN, MEMBER, IEEE
}

\begin{abstract}
Problems intrinsic in self-balancing Wheatstone bridges have led to the development of a new de substitution microwave power meter. The new instrument allows four-terminal measurement of bolometer resistance and affords improved accuracy and lower noise at a lower cost than earlier instruments. Measurement errors due to imperfect behavior of the servo system are typically less than $\mathbf{0 . 0 1}$ percent.
\end{abstract}

\section{INTRODUCTION}

HOR MR MANY YEARS the highest accuracy in microwave power measurements in the range from 0.1 to $10 \mathrm{~mW}$ has been achieved with bolometers, using dc substitution techniques. The first such precision instrument was a self-balancing Wheatstone bridge described by Engen in 1957 [1]. In 1970, we described an improved instrument which also was a self-balancing Wheatstone bridge but included a power-leveling capability and a differential voltmeter [2]. We now describe a new dc substitution power meter which provides certain advantages over the earlier instruments in lower cost, greatly simplified circuitry, improved signal-to-noise ratio in the output signal, and the reduction or elimination of certain errors.

\section{BACKGROUND}

Fig. 1 shows the form of the original self-balancing Wheatstone bridge, with a bolometer in one arm. The operational amplifier senses the error voltage across the horizontal diagonal of the bridge and drives the top of the bridge to heat the bolometer to a point which closely approximates bridge balance. The voltage across the vertical diagonal is measured before and after the RF power is applied, and the unknown RF power is related to the change in the computed dc power in the bolometer through the constants of the bolometer mount.

This straightforward approach is subject to certain problems, however. First, as RF power is dissipated in the bolometer, the common-mode voltage at the amplifier input changes; therefore, an amplifier having a high common-mode rejection ratio (CMRR) is required for accurate measurement. Second, the bolometer is a two-terminal device which typically must be located at some distance from the other three arms of the self-balancing bridge, since in most systems, the terminal surface of the RF portion of the system dictates the physical location of the bolometer mount. It is not common practice, nor is it usually feasible, to separate the resistances associated with

Manuscript received June 30, 1976.

The author is with the Electromagnetics Division, National Bureau if Standards, Boulder, CO 80302.

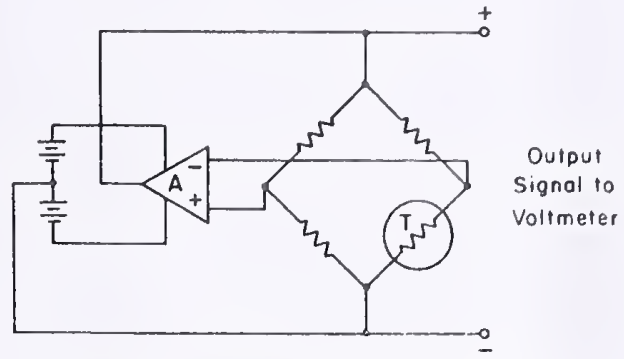

Fig. 1. Self-balancing Wheatstone bridge.

the leads to the bolometer from the bolometer itself. This causes a first-order error in the measurement of the substituted power unless the actual lead resistances are measured separately, and corresponding corrections calculated for each different set of leads.

The third problem is more subtle. Consider equivalent noise-voltage generators in series with each of the input leads of the balancing amplifier. If there is no feedback from the output of the amplifier to the inverting input, then the noise will be amplified by the full open-loop gain of the amplifier and will appear at the top of the bridgethe point from which the output signal is taken. Since it is the purpose of the servo system to maintain the bridge in balance as exactly as possible, the result is a closed-loop gain for noise that is higher than the closed-loop gain for the dc signal (at those frequencies where the attenuation of the feedback path is high and the amplifier has gain). This conflict is an intrinsic problem in all systems which use a self-balancing dc bridge.

\section{The Basic Circult}

Active measuring circuits of various kinds incorporating operational amplifiers and isolated power supplies are not new. In 1954 Hoge [3] proposed a manually balanced circuit for the intercomparison of two four-terminal resistors. Although his system was manually operated, his concept bears some interesting similarities to the circuit described below. Others [4], [5] have reported on resistance ratio measurement techniques involving operational amplifiers. However, the prior work has dealt exclusively with linear systems involving linear resistances. In Fig. 2, an operational amplifier and associated power supply are connected with two four-terminal resistors and an external voltage source in such a way that a current $I$, flows through $R_{1}$. Under the assumption of an ideal amplifier, the current will flow as shown, and because by hypothesis no currents flow in the amplifier input leads, exactly the same current flows out of the power supply common terminal bark 


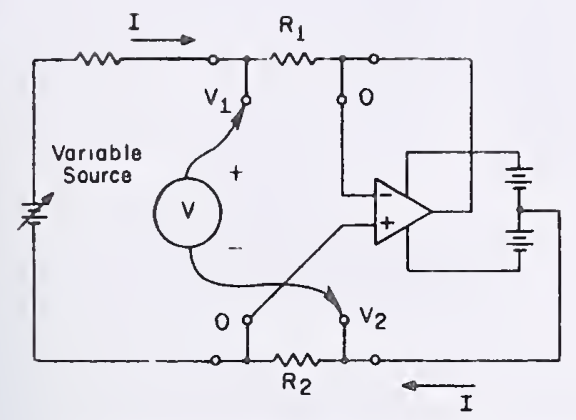

Fig. 2. A method for intercomparing two four-terminal resistors.

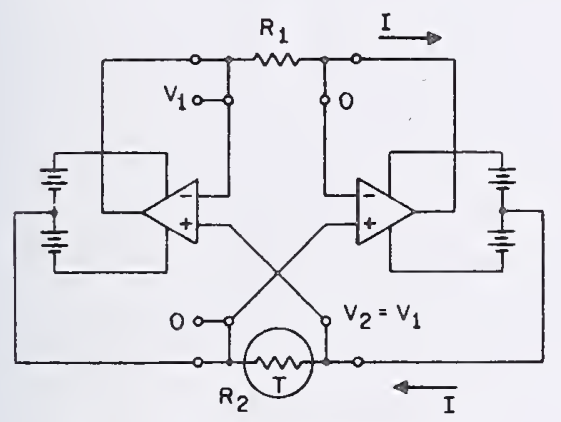

Fig. 3. A self-adjusting current loop.

ugh $R$, to the adjustable source. The amplifier mainFains the current at such a level as to keep a zero potential difference between its input leads at all times. A voltmeter cunnected between the other two potential terminals of $R_{1}$ and $R_{2}$ will display a reading which is proportional to the difference in resistance between $R_{1}$ and $R_{2}$.

Now consider replacing $R_{2}$ by a negative temperature crefficient bolometer (a thermistor). If the source is varied, the current $I$ will vary. This will cause the bolometer resistance to change and will produce a varying indication on the voltmeter. This immediately suggests closing a second feedback loop in such a way that the source voltage is cuntrolled by the voltmeter reading to produce a voltmeter reading of zero. 'I'his concept is shown in Fig. 3, where the voltmeter and source have been replaced by a second operational amplifier and its power supplies. If a current $I$ flows through $R_{1}$, by the previous argument, the current flowing through $R_{2}$ is identically the same. The anplifiers maintain a zero potential difference across their respective inputs by controlling these identical currents. Thus, since $R_{1}$ and $R_{2}$ have identical voltage drops across them for identical currents, $R_{2}$ must be equal to $R_{1}$. This circuit therefore forces the bolometer resistance into equality with $R_{1}$, and it does so on a four-terminal hasis. This allows the elimination of the lead-error problem intrinsic to a Wheatstone bridge. The circuit has two stable states, since the current can, in principle, flow in either clirection. However, once the current flow has been esPilied, the self-balancing servo is quite stable. It is a inial inatter to provide for a predetermined direction of llow in an actual instrument.

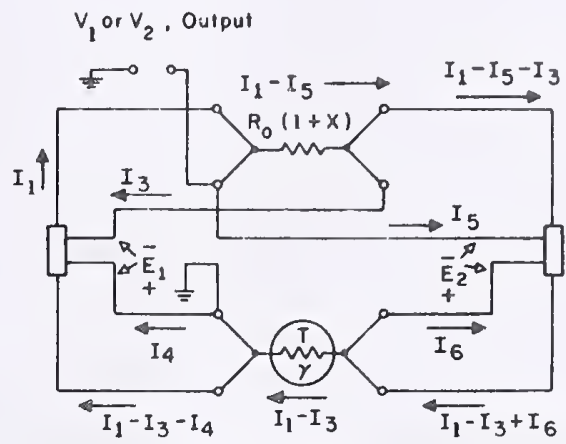

Fig. 4. Frror sources in the loop. Current $I_{1}$ is the desired bolometer current.

The circuit also has interesting symmetry properties. For example, in one configuration the amplifier common-mode voltages are identically zero if the lead resistances are zero. This would allow the use of chopper-stabilized three-terminal amplifiers instead of differential amplifiers. Finally, the system works equally well with positive temperature coefficient bolometers (barretters) by interchanging the bolometer and $R_{1}$. In all, a total of eight configurations result from various combinations of amplifier configurations and bolometers.

\section{ERROR ANALYSIS}

The error sources in the system due to the limitations of the operational amplifiers and the reference resistor $R_{1}$ are shown in Fig. 4. The assumptions are that the amplifier input bias currents are small but finite, that leakage currents flowing into or out of each operational amplifier and its power supplies are negligibly small, and that the amplifier input offset voltages are small but finite. The amplifier gain is assumed to be large but finite. Equation (1) summarizes the results of the analysis.

$$
\begin{aligned}
P & =\frac{\left(2 V_{1}-V_{3}\right) V_{3}}{R_{0}} \\
& \cdot\left[1-X-\frac{E_{1}}{2 V_{1}-V_{3}}\left(1-\frac{R_{0}^{2}}{\gamma V_{1}\left(V_{1}-V_{3}\right)}\right)\right. \\
& -\frac{E_{2}}{2 V_{1}-V_{3}}\left(1+\frac{R_{0}^{2}}{\gamma V_{1}\left(V_{1}-V_{3}\right)}\right) \\
& +\frac{R_{0}\left(I_{3}-I_{5}\right)}{2 V_{1}-V_{3}}\left(1-\frac{R_{0}^{2}}{\gamma V_{1}\left(V_{1}-V_{33}\right)}\right) \\
& \pm \frac{2}{2 V_{1}-V_{3}}\left(V _ { 1 } \left(x_{1}+S_{1} \beta_{1}+\left(V_{1}-V_{33}\right) \alpha_{3}\right.\right. \\
& \left.\left.+\frac{\left(V_{1}-V_{3}\right) S_{33} \beta_{3}}{V_{3}}\right)\right]
\end{aligned}
$$

where

$$
\begin{aligned}
V_{1} & =\text { output voltage with no } \mathrm{RF} \text { power } \\
V_{3} & =\text { output voltage with } \mathrm{RF} \text { power } \\
V_{1} & =V_{1}-V_{2} \\
\gamma & =\text { bolometer coefficient } \Omega / \mathrm{W}
\end{aligned}
$$




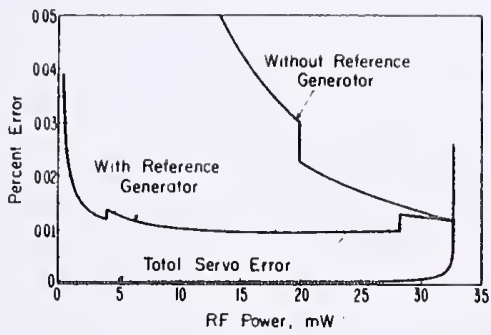

Fig. 5. Voltmeter errors with and without offsetting reference voltage generator. 'Total servo errors with bias currents of $6 \mathrm{nA}$ and amplifier offsets of $10 \mu \mathrm{V}$.

$S_{1}, S_{2}, S_{3}=$ range (full scale) of the external voltmeter when measuring $V_{1}, V_{2}$, and $V_{3}$, respectively

$\alpha_{1}, \alpha_{2}, \alpha_{3}=$ fraction of reading error in the external voltmeter when measuring $V_{1}, V_{2}$, and $V_{3}$, respectively

$\beta_{1}, \beta_{2}, \beta_{3}=$ fraction of full scale error in the externa voltmeter when measuring $V_{1}, V_{2}$, and $V_{3}$, respectively.

The remaining terms in the equation are shown in Fig. 4. Error voltages $E_{1}$ and $E_{2}$ are due to the combined effect of amplifier offset and finite gain. The loop current is $I_{1}$, and $I_{3}$ through $I_{6}$ represent the amplifier input bias currents. The nominal resistance of the reference resistor is $R_{0}$, and it may be in error by the fractional amount $X$. The bolometer is represented by the element $T$, which has an ohms-per-watt coefficient $\gamma$.

The first error term is due to the reference resistor and is not dependent on the RF power level. The second term is due to the finite amplifier gains and offsets and is a function of the RF power level. The third term is due to the amplifier input bias currents. Note that two of the four bias currents, $I_{4}$ and $I_{6}$, do not appear in the equation because they do not flow through either of the resistors in the configuration which was shown in Fig. 4. The servo errors in (1) are plotted in Fig. 5 for a typical coaxial dual-element thermistor mount with an ohms-per-watt coefficient of 13000 and a bias current of $12.8 \mathrm{~mA}$. The normal maximum RF power level for this type of mount is limited to 10 $\mathrm{mW}$ because of the dual-element substitution error; however, the curves have been continued to current cutoff to show the behavior of the errors. Only the power-dependent errors are shown here. The errors due to the external voltmeter are also shown in the upper two curves. If a stable variable voltage source (i.e., a "reference generator") is used to offset the voltmeter so that it is always used at as great a fraction of full-scale indication as possible, the middle curve results. If the reference generator is not used, then the voltmeter errors are magnified by using it to measure two voltages $\left(V_{1}\right.$ and $\left.V_{2}\right)$ which are nearly the same, and then taking the difference of the squares.

We have described the errors due to the limitations of operational amplifiers and resistors. Unfortunately, the principal source of error in an actual powar measurement is the limited accuracy of the external voltage measuring equipment. The errors due to the voltmeter alone are typically 20 times those due to the servo, with voltmeter specifications typical of high quality digital instruments.

\section{Practical Realization}

The unique features of the self-balancing circuitry described above make this instrument especially attractive in applications where automatic control is desired. It is often necessary to assemble several power meters in a given system, one for each of several output ports. The use of four-terminal connections to both the reference resistor and the bolometer make it possible to bring long leads from

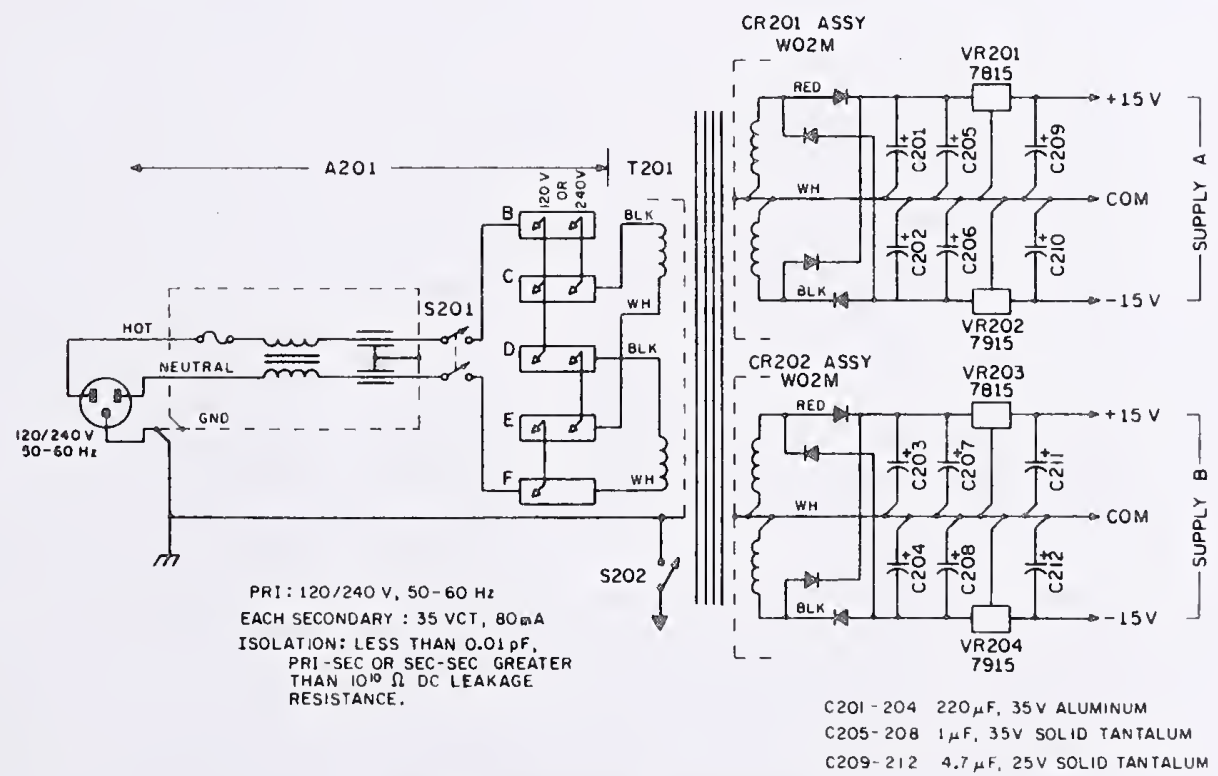

Fig. 6. Dual isolated power supplies. 
C

1 


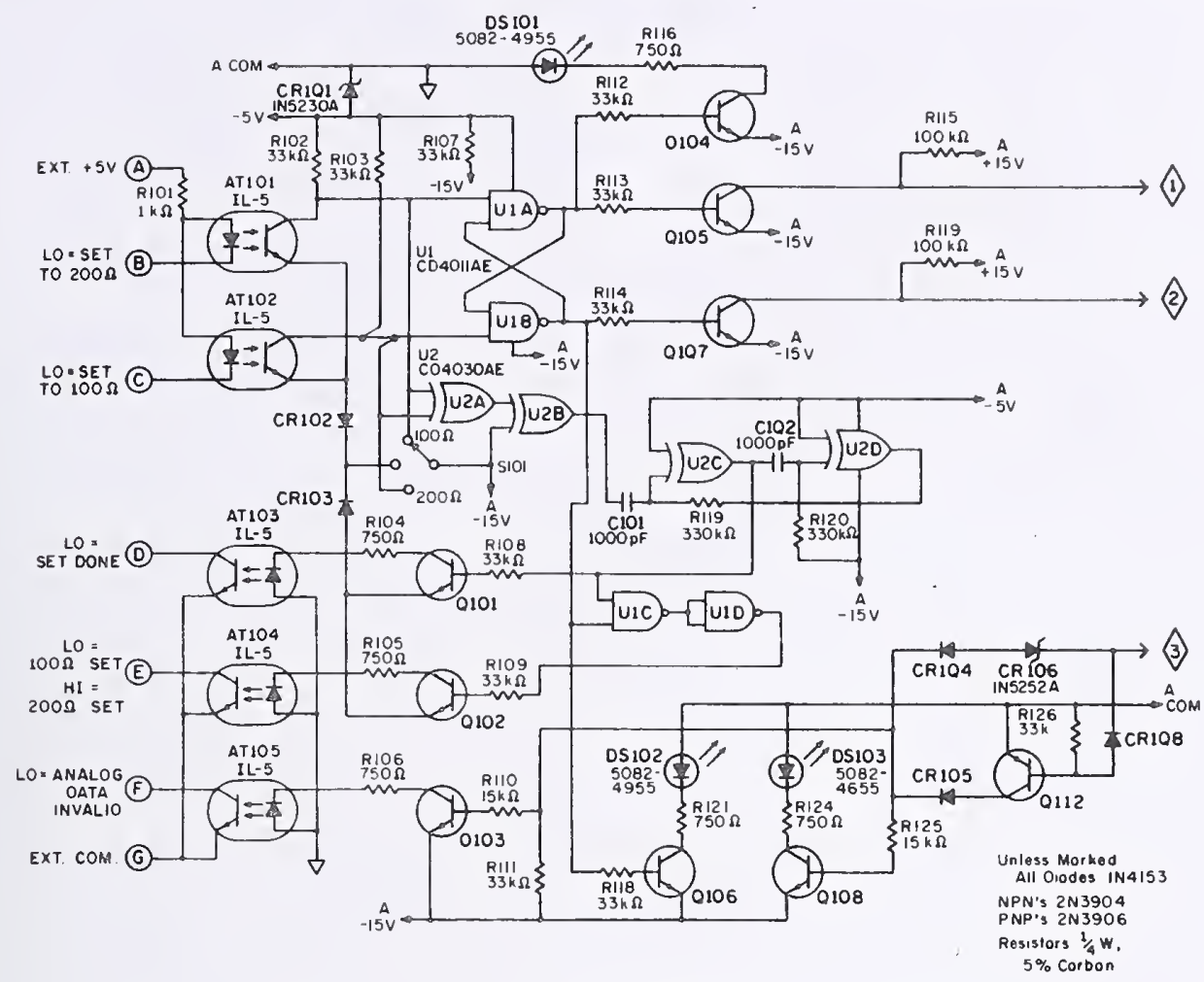

Fig. 7. Interface logic.

the bolometer units to a central instrumentation console without introducing errors. In addition, it is now possible to control the operating resistance of the bolometer unit by changing the reference resistor in response to an electrical control signal. This is much more difficult to do in a Wheatstone bridge because the contact resistance of the switches cannot be entirely removed from the bridge circuit. Now, however, it is possible to use field-effect transistor switches with no degradation in the measurement accuracy.

A complete schematic diagram is shown in Figs. 6, 7, and 8. The bulk of the circuitry is involved with the interface between the power meter and an external controller. The self-balancing portion is shown in Fig. 8. The reference resistor is comprised of $R_{129}$ through $R_{136}$. It is arranged in such a way that by switching the current terminals, the effective resistance can be changed from 100 to $200 \Omega$. This switching is accomplished by the field-effect transistors. In addition, by removing AR101 from its socket, these resistors can be calibrated against an external four-terminal standard attached to the bolometer terminals using essentially the technique shown in Fig. 2.

The remote control inputs are applied at the left side of Fig. 7 through optical isolators. They allow an external controller to set the mount operating resistance to either 00 or $200 \Omega$. The mount operating resistance is determined by S101: $100 \Omega$, REMOTE, and $200 \Omega$. When in the REMOTE position, a negative-true pulse applied to ter- minals $B$ or $C$ will set the operating resistance accordingly. An elementary "hand-shake" return signal is provided at Pin $D$ and a logic level confirming that the correct resistance was set appears at $\operatorname{Pin} E$.

If the balancing servo goes out of control due to RF overload, broken or shorted lead wires, switching transients in changeover from one operating resistance to another, or a burned-out bolometer, then a front panel warning light appears, and a control signal appears between Pins $F$ and $G$ of the interface. This signal may be used to protect bolometer mounts against RF overload or to prevent the data acquisition portion of the system from taking invalid data.

The instrument as shown is designed to accept only negative temperature coefficient bolometers. The addition of a barretter capability requires only the incorporation of a 4PDT switch to interchange the amplifier input leads for example.

The signal output to the external voltmeter may be taken either from a terminal pair which is switched automatically as the mount operating resistance is switched, or from terminals connected directly to the reference resistor if the on-resistance of the switches cannot be tolerated. This resistance is less than $50 \Omega$. The Thevenin equivalent source resistance measured, for example, between terminals 2 and $E-$ in Fig. 8 , is very small (microohms) because of the large amount of feedback in the loop. 


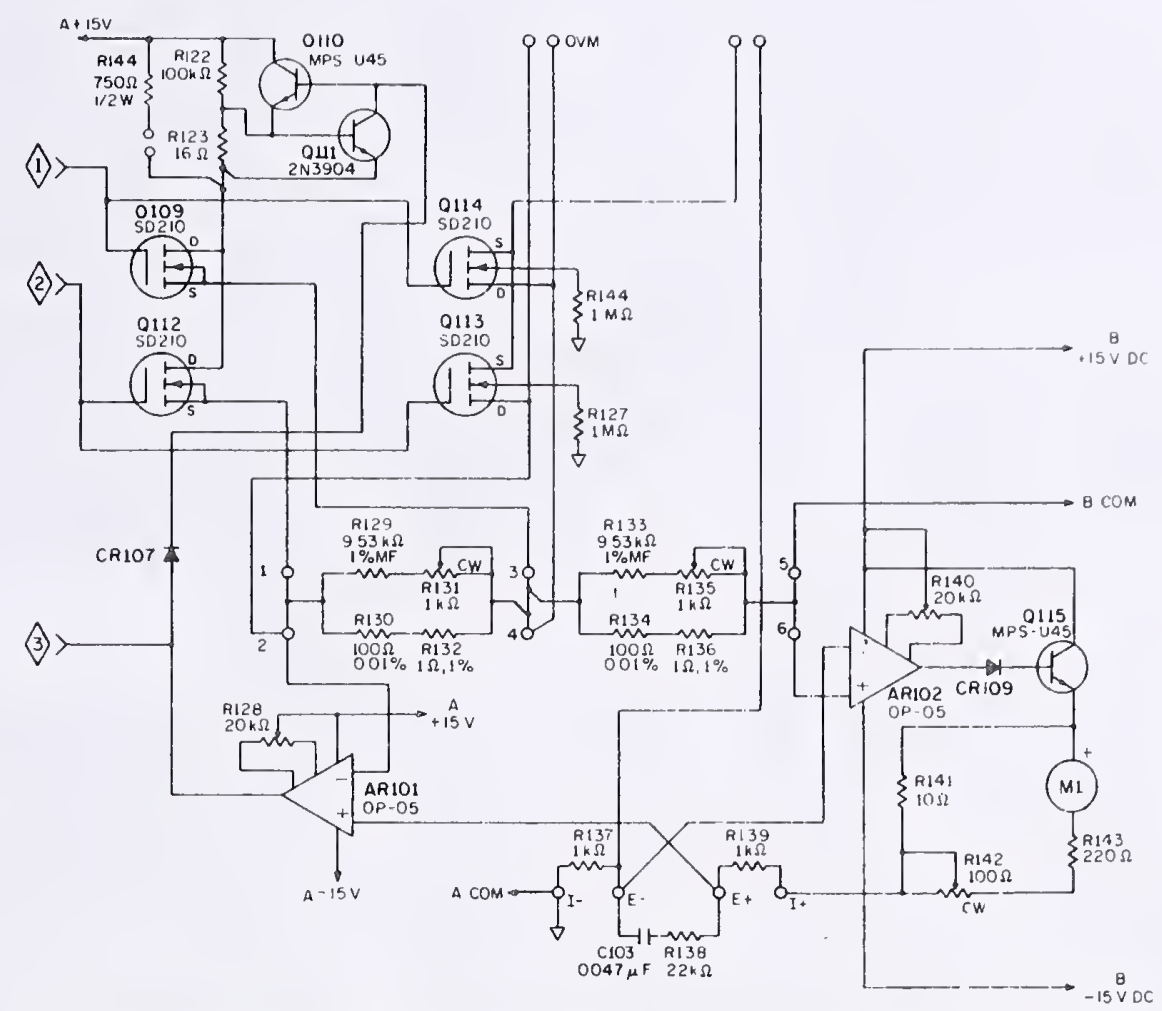

Fig. 8. Self halancing current lo(l). The bolometer is connected to the terminals identified hy $I-E-, E+$, and $I+$

\section{PERFORMANCE}

Performance of the instrument was measured in two ways. First, the magnitudes of the offset voltages and bias currents were measured under conditions of changing RF power to verify that the values used for these terms in the error analysis were realistic. Second, a system was assembled that allowed a comparison of the new instrument with an NBS Type II power meter. Mounts for the two power meters were attached to two arms of a "magic tee" or other power divider. The Type II was used to control and measure the power level from a source, while the Type IV measured the power on the other arm. The two power levels were nominally equal. The entire measurement system was under the control of a programmable calculator. Power levels were selected at random by the calculator, typically over the range of 0.1 to $15 \mathrm{~mW}$, and the ratio of the bolometric powers at the two ports computed. The independence of this ratio was a measure of the precision of the two power meters and of their relative linearity. The standard deviation of a series of 1024 measurements of randomly selected levels was about 0.008 percent. The series was repeated several times for different combinations of single and dual-element mounts, with similar results. Since the two power meters were quite different internally, this is also indicative of the absolute linearity of each.

\section{SUMMARY}

We have described a new dc substitution self-balancing $\mathrm{RF}$ power meter which is not a form of Wheatstone bridge. Its advantages include reduced cost, lower noise, improved ease of adjustment, and adaptability to automatic control. A disadvantage is the requirement for a highly isolated power supply. 'The technique may also be useful with hot-wire anemometers. A patent is pending.

\section{ACKNOWLEIMGMENT}

The author wishes to acknowledge the contributions of G. Reeve in early discussions, and the construction of the prototype instrument by W. Boone. This work was supported in part by the U.S. Army, U.S. Navy, U.S. Air Force, and the Energy Resources Development Administration.

\section{REFERENCFS}

[1] (i. F. Lingen, "A self-balancing direct-current bridge for accurate bolometric power ineasureineut," NHS' J Res., vol. 59, no. 2, pp. 10) 105, Aug. 1957 .

[2] N. 'T' Larsel and F'. IR ('lague, "The NBS type II power measurement system," Adv. Instrum, vol. 25, Pt. 3, paper no. 712-70, in Proc. 25th Allnu lis Conf. (I'hiladlelphia, PA), Oct. 26-29, 1970.

|.3 H. J. Hoge, "A two emf nethod for the comparison of resistances," Re'. Sici Instrum., vol. 25, mo. 9, pp. 902).9(17, Sept. 1954

[4] L. Crovini and ('. C. M Kirlsy, "IResistance comparisons at nanovolt levels using an isolating corrent ratiogenerator," Rev. Sci. Instrum. vol. 41, 110, A, prs. 49:3 497, Apr 1970.

|5| M. I. Roberts, "I'utent in+lucl ric bridge for resislance thermometry,"

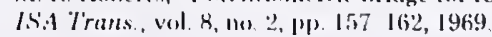


